\title{
Coal phase out and renewable electricity expansion under Paris targets
}

\section{Steve Pye ( $\nabla$ s.pye@ucl.ac.uk )}

University College London

\section{Isabela Butnar}

University College London

Shivika Mittal

Imperial College London

\section{Sara Giarola}

Imperial College London

\section{Adam Hawkes}

Imperial College London

\section{Agnes Beltramo}

KTH Royal Institute of Technology

\section{Will Usher}

KTH Royal Institute of Technology

\section{Maarten Brinkerink}

University College Cork

Paul Deane

University College Cork

\section{Liliana Benitez}

University College Cork

Taco Niet

Simon Fraser University

Abhishek Shivakumar

University College Cork

\section{Short Report}

Keywords: Integrated assessment modelling, coal phase out, climate policy

Posted Date: April 29th, 2021

DOI: https://doi.org/10.21203/rs.3.rs-380763/v3 
License: (c) (i) This work is licensed under a Creative Commons Attribution 4.0 International License. Read Full License 


\title{
Coal phase out and renewable electricity ex- pansion under Paris targets
}

\author{
Steve Pye, Isabela Butnar (University College London) \\ Shivika Mittal, Sara Giarola, Adam Hawkes (Imperial College London) \\ Agnese Beltramo, Will Usher (KTH Royal Institute of Technology, Sweden) \\ Maarten Brinkerink, Paul Deane, Liliana Benitez (University College Cork) \\ Taco Niet (Simon Fraser University, Canada) \\ Abhishek Shivakumar (Climate Compatible Growth)
}

Introduction

The case for rapid coal phase-out

The rapid rise of renewable electricity deployment

Exploring a clean energy transition

Approach to modelling

Model results

Global transition pathways

Regional grids and coal phase out

Conclusions

Declarations

References

Appendices

Appendix A. Model descriptions

Appendix B. Modelling assumptions for IAMs

Appendix C. Selected additional model results on generation capacity

This paper provides insights into the implications of a global coal phaseout in the power generation sector across different regions under international climate targets. Using modelled scenarios, we highlight the strong rate of decline in new build and decommissioning of existing coal assets, and the growth in renewable capacity to not only fill the gap but meet growing demand for electricity. We find that key uncertainties exist across many of these pathways towards system decarbonisation. We also explore how regionally connected grids can help in transitioning away from coal whilst ensuring supply of electricity. Focusing on potential interconnection between India and the Gulf region, we find that this can be an important strategy for helping enable the transition based on increasing renewables, with regional interconnection encouraging coal phaseout even without a specific coal phase-out target. The technical modelling in this report requires further consideration, in respect of the other multiple benefits of a transition 
towards low carbon generation, but also the policy mechanisms that will enable delivery of what is a hugely challenging transition.

\section{Introduction}

While the Paris Agreement developed at COP21 strengthened international consensus on the need to tackle climate change, COP26 provides an opportunity to develop and expand initiatives that bring about real change on the ground. This is particularly important as different countries start to reinvest in their economies following the Covid 19 pandemic, with current plans suggesting many countries are foregoing the opportunity to build back greener (Vivid Economics, 2021). One such initiative being focused on at COP26 is the Powering Past Coal Alliance (PPCA) ${ }^{1}$, aimed at achieving phase out of existing coal generation plant and a moratorium on building new unabated coal, and in doing so, accelerating the pace of the transition towards clean energy. If the international community is to get close to its common climate goals, strong efforts will be needed, and enabled through effective policies and financing, recognising that many countries will potentially be foregoing the full benefits of existing assets.

\section{The case for rapid coal phase-out}

Coal generation continues to be the largest single source of electricity globally, providing $37 \%$ of the total generation in 2019. While renewable growth since 2010 has seen its generation share increase from $20 \%$ to $27 \%$, this has not signficantly displaced coal, which accounted for $40 \%$ in 2010 . Coal generation accounts for $64 \%$ of global coal consumption, and therefore is a huge source of GHG emissions, accounting for almost $30 \%$ of total $\mathrm{CO}_{2}$ emissions from the energy sector (IEA, 2020).

From the recent IPCC report on $1.5^{\circ} \mathrm{C}$, most scenarios see coal generation declining to a $7 \%$ share in 2030 and less than 1\% in 2050, with no new investment from 2030 (Rogelj et al., 2018). However, it has also been estimated that current and proposed infrastructure, with the largest share in the power sector, would result in global carbon budgets being exceeded (Tong et al., 2019). This means the need for a halt on building new coal plant but also lower utilisation and early retirement of existing plants, many of which have been built in recent years. While the rate of commissioning of new coal plants has been in decline, 2019 saw growth in total coal capacity, with a net increase of $34 \mathrm{GW}$ to global fleet of $2044 \mathrm{GW}$. In addition, some $200 \mathrm{GW}$ is currently under construction, and will likely to be utilised to some extent (Shearer et al., 2020).

Some countries are much more dependent on coal generation than others, and therefore face significantly higher challenges to transition. China for example sourced $65 \%$ of its generation from coal, while for India it was higher, at $72 \%$. Combined, these countries account for $61 \%$ of global coal generation capacity (IEA, 2020). More broadly, there are key issues around the political economy of different countries, with interests in maintaining coal investment (Dorband et al., 2020) and concerns around socio-economic impacts (system resilience, employment), with many major coal-using countries some distance from starting a transition away from coal (Spencer et al., 2018). While the PPCA is being used to develop momentum for this transition, many of the larger coal generating countries have not joined, limiting its potential impact (Jewell et al., 2019). It will therefore be crucial for PPCA countries to explore ways of supporting other high coal dependent countries transition to lower carbon systems.

\section{The rapid rise of renewable electricity deployment}

While the phase out of coal generation is imperative for tackling climate change, the increased deployment of renewable electricity to both replace coal generation and meet increasing demand will be critical. Renewable generation capacity has seen rapid growth in recent years, with total global capacity at over $2500 \mathrm{GW}$ in 2019, with solar and wind

1 PPCA Global Summit strengthens international commitment to accelerate coal power phase-out ahead of COP26, https://poweringpastcoal.org/news/PPCA-news/ppca-global-summitstrengthens-international-commitment-to-accelerate-coal-power-phase-out-ahead-of-cop26 
accounting for $586 \mathrm{GW}$ and $623 \mathrm{GW}$ respectively. Since 2012, the majority of new additions to generation capacity have been from renewables, and in 2019, they accounted for over $70 \%$ of new global generation additions (IRENA, 2020a).

This continued growth reflects the large cost reductions in solar and wind technologies, which now constitute the lowest cost forms of generation in many parts of the world. Solar costs fell by $82 \%$ between 2010 and 2019, from $37.8 \mathrm{c} / \mathrm{kWh}$ to $6.8 \mathrm{c} / \mathrm{kWh}$ (2019 USD) (IRENA, 2020b), and are expect to further decline by over $50 \%$ to less than 3.4 c/kWh by 2030 (IRENA, 2020c).

Much of the scenario modelling of energy transitions has shown a pivotal role for renewable generation (IRENA, 2020c; Jaxa-Rozen and Trutnevyte, 2021; Rogelj et al., 2018), as the basis for replacing fossil generation, but also as the basis for system growth, as end use sectors increasingly electrify, requiring higher levels of supply. However, concerns remain about high levels of renewable integration, and whether scenario analysis is effectively capturing these challenges (M Brinkerink et al., 2021), including the need for flexibility through dispatchable generation capacity, storage, interconnection and demand side management.

\section{Exploring a clean energy transition}

Using scenario modelling, this paper explores the rate of transition away from coal to renewables in the electricity generation sector, in the context of pursuing a Paris-aligned target of 'well below $2^{\circ} \mathrm{C}^{\prime}$ (United Nations, 2015). It shows electricity generation pathways to 2050, including required rates of deployment of renewables and coal phase out across different regions. The role of regions in effecting this change differs depending on their current and planned coal generation, the rate at which renewable capacity can be deployed, and the role that interconnected grids can play in moving large levels of renewable electricity to high demand regions. These differences are illustrated by focusing on high coal dependent regions and lower coal dependent regions.

Given this context, a case study for the India-Gulf region is also undertaken, to explore how regionally-interconnected grids can help facilitate the transition away from coal and how they can assist with mitigating the variability in supply from renewables such as solar and wind.

It is important to note that this is a technical modelling focused study, providing insights on what needs to happen to achieve Paris-aligned targets, and how this transition can be aided by region-interconnected grids. Issues of political feasibility are not considered in detail, but are critical to the prospects of realising a Paris-compatible transition. This is very much an area for further research, and which will be a core focus of scenario modelling under the Climate Compatible Growth (CCG) programme.

\section{Approach to modelling}

There are two parts to the modelling approach; the first explores global transitions towards a low carbon generation system, and therefore a phase out of coal and other unabated fossil fuel generation. The second part focuses on the region of India as a case study, and the potential for facilitating the transition towards a renewable dominant system via a regional grid encompassing the Gulf-South Asia region.

In the first part, we explore this transition with a set of Integrated Assessment Models (IAMs), namely TIAM-UCL, TIAM-Grantham, MUSE and GLUCOSE (details in Appendix A). These IAMs focus on the whole system transitions towards a net-zero emissions economy, notably through growth in renewables but also other low carbon energy vectors, and the move away from fossil fuel supply, including coal phase out in the generation and other sectors. All models provide metrics on coal phase out, renewable energy deployment, and the wider system transition across the range of economic sectors e.g. industry, transport, buildings, agriculture etc.

The benefit of using a model ensemble is to provide insights into some of the differences they present with respect to possible transition pathways. As seen in the results in this study, some models show a stronger push to electrification, while others rely more heavily on other vectors such as biofuels and hydrogen. Given the number of models involved, a model protocol was first developed to ensure reasonable consistency 
between the model teams, with key assumptions listed (Appendix B). The key elements of the protocol included:

- Two core scenarios. i) An NDC scenario reflects current country pledges to 2030, and extends these out to 2050. TIAM-UCL and TIAM-Grantham assume constant emissions per unit of GDP post 2030, resulting in little or no net $\mathrm{CO}_{2}$ emission reduction as compared to today's values. MUSE incoporates more ambitious decarbonisation in this scenario, by assuming that the emission reduction per unit of GDP achieved between 2015 and 2030 in each region continues after 2030. An NDC scenario was not developed using GLUCOSE. ii) A scenario compatible with the Paris Agreement limits the global temperature increase to $1.75^{\circ} \mathrm{C}$ above pre-industrial level by 2100 , at a $66 \%$ probability. This is based on a global carbon budget of $800 \mathrm{GtCO}_{2}$ from 2018 onwards (equivalent to around 20 years worth of current emissions).

- Socio-economic drivers of population and economic growth defined using SSP2 (Fricko et al., 2017), a 'middle of the road' case from the Shared Socio-economic Pathways (SSPs) classification (van Vuuren et al., 2017)

Given the timescale of the study, further alignment between models was not deemed possible.

In the second part, two models, OSeMOSYS Global and PLEXOS-World, have been used to assess coal phase out at a regional level, and the potential for the development of a regionally-interconnected grid. The selected case study region is India, with its large coal generation fleet, and the Gulf region with high renewable potential. The OSeMOSYS Global model is used for exploring the future capacity expansion of the generation system, as part of the overall system transition, given regional carbon budgets, demand drivers etc. It builds on other work undertaken under the CCG programme, under the Gulf Underwater Interconnector (GUI) project. The PLEXOS-World model is linked to OSeMOSYS Global, using the results from the long-term planning exercise as the basis for an operational analysis of the power system by applying hourly unit commitment and economic dispatch simulations.

\section{Model results}

This section of the paper is split in two. First we describe the key results from the global IAMs and the regional implications for growth in renewable generation and the transition away from coal power. On regional perspectives, we have allocated countries in to three groups. This is based largely on the timetable for coal phase out used in the Inevitable Policy Response scenario exercise (as described in Vivid Economics and UCL (2020)), with lower coal dependent and often higher income countries phasing out coal more rapidly, with a slightly slower phase out for higher coal dependent countries and regions.

Table 1. Country groupings for presenting regional results

\begin{tabular}{|l|l|l|}
\hline Group name & Countries & Description \\
\hline $\begin{array}{l}\text { Lower Coal De- } \\
\text { pendent (LCD) }\end{array}$ & $\begin{array}{l}\text { EU, USA, UK, Canada, } \\
\text { Japan, South Korea, } \\
\text { Australia, Mexico }\end{array}$ & $\begin{array}{l}\text { These are higher income countries and regions, } \\
\text { mainly in the OECD, many of whom have seen } \\
\text { reductions in coal generation in recent years. }\end{array}$ \\
\hline $\begin{array}{l}\text { Higher Coal De- } \\
\text { pendent (HCD) }\end{array}$ & $\begin{array}{l}\text { China, India, Other } \\
\text { Developing Asia }\end{array}$ & $\begin{array}{l}\text { These are large emerging economies who have } \\
\text { rapidly expanded their energy systems, and } \\
\text { have a stronger dependency on coal generation. }\end{array}$ \\
\hline Other & $\begin{array}{l}\text { Latin America, Russia } \\
\text { and former Soviet } \\
\text { states, Middle East, Af- } \\
\text { rica }\end{array}$ & $\begin{array}{l}\text { Other regions that do not fit into the above cat- } \\
\text { egory, but who are are less dependent on coal } \\
\text { use. }\end{array}$ \\
\hline
\end{tabular}

Secondly, we focus on a regional case study to explore how regionally-interconnected grids could help realise this transition, by moving high levels of renewable generation to areas of high electricity demand previously reliant on coal generation. 


\section{Global transition pathways}

An $800 \mathrm{GtCO}_{2}$ carbon budget (from 2018), as used in this modelling for the $1.75^{\circ} \mathrm{C}$ case, requires rapid reductions in $\mathrm{CO}_{2}$ emissions by mid-century (Figure 1). Under this scenario, net-zero emissions are reached around 2060 in the case of TIAM-UCL and MUSE, and soon after 2070 in TIAM-Grantham; GLUCOSE has a lower ambition 'below $2{ }^{\circ} \mathrm{C}^{\prime}$ case so sees a slower decline to net-zero in the post-2050 period (a budget of $\sim 1400 \mathrm{GtCO}_{2}$ ). Year-on-year reduction rates of 7-9\% are observed for TIAM-UCL and MUSE prior to 2050 (see Figure 1). A slower rate for TIAM-Grantham reflects much larger levels of negative emissions post-2050, meaning less mitigation is required prior to 2050. The NDC emission trajectories are more divergent, reflecting some differences in how the current policies have been modelled post 2030 (as described earlier).

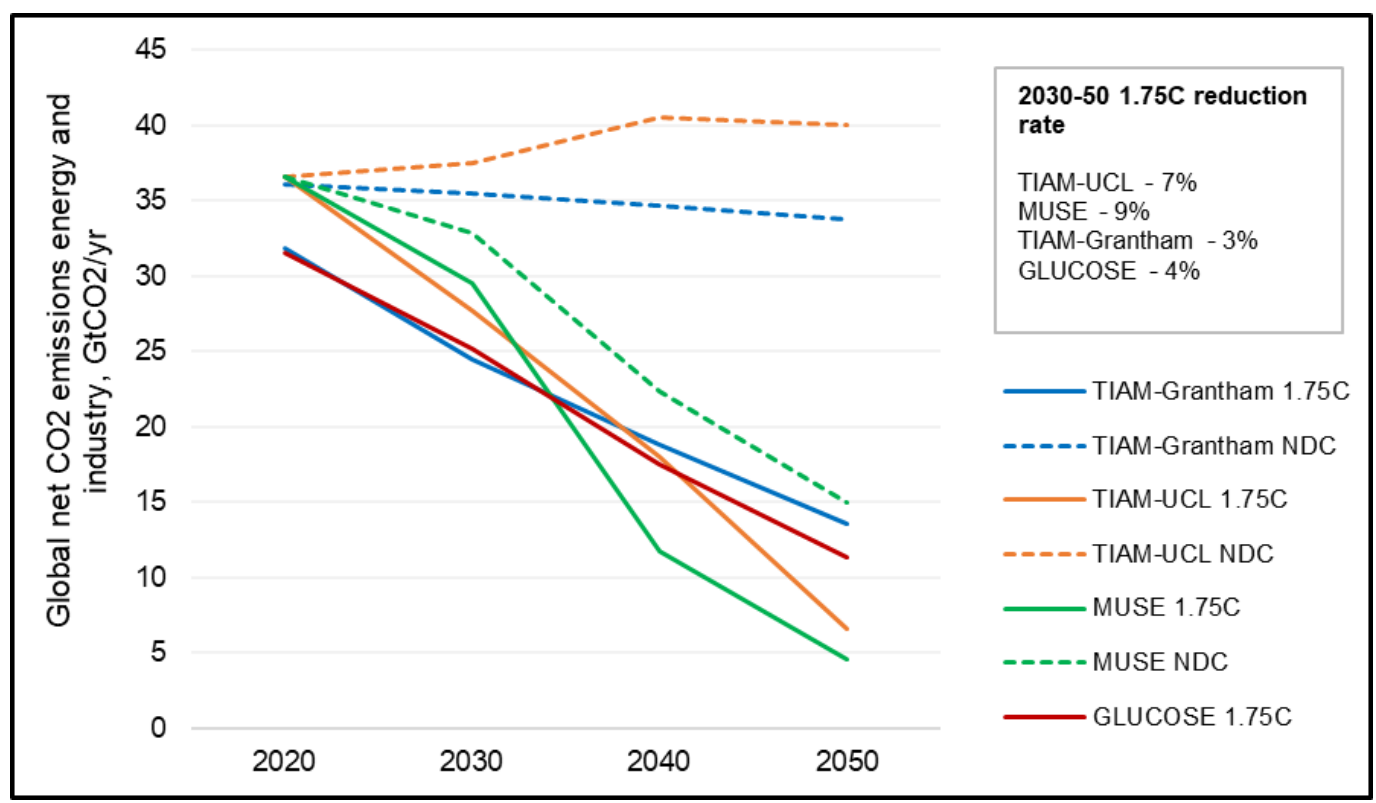

Figure 1. Global net $\mathrm{CO}_{2}$ emissions from energy use and industrial processes for NDC and $\mathbf{1 . 7 5}^{\circ} \mathrm{C}$ scenarios, 2020-50. This graph only includes $\mathrm{CO}_{2}$ emissions from energy use and industrial processes, net of engineered removals (CCS / DAC). ${ }^{2}$ AFOLU emissions are not presented, but are included in the analysis for TIAM-UCL and GLUCOSE. Some differences in 2020, showing lower emissions, reflect 2020 being a modelled rather than a calibrated period.

As implied by the emission trajectories above, a shift to a lower carbon generation system is critical to meet global climate targets. Not only does electricity need to be decarbonised (as a large source of emissions) but will also need to be expanded to meet increased demand (based on population and economic growth, and currently unmet demand) and the increasing electrification of end use sectors. From the SR1.5 scenario ensemble (Huppmann et al., 2018), we can observe a wide range in electricity generation system size (120-310 EJ, 170-230 EJ IQR), reflecting differing assumptions in relation to growth drivers of low carbon technologies, in particular renewables (Figure 2 ). The role of Carbon Dioxide Removal (CDR) technologies, and of other low carbon vectors e.g. hydrogen, will also influence the relative role electricity plays.

TIAM-UCL suggests much higher rates of deployment of low carbon electricity than assumed in other models utilised in this modelling excercise, driven by continued rapid growth of renewables - and is near the top of the IPCC scenario range in 2050 (290 EJ). This much stronger role for electricity as a basis for decarbonisation across sectors contrasts with other models. MUSE, for example, has a much stronger reliance on

2 To achieve the $1.75^{\circ} \mathrm{C}$ target, the models utilise different levels of $\mathrm{CO}_{2}$ removal. By 2050 the

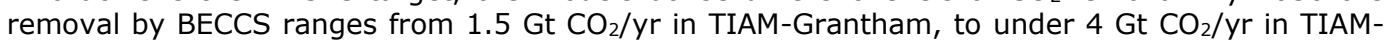
$\mathrm{UCL}$ and $6 \mathrm{Gt} \mathrm{CO}_{2} / \mathrm{yr}$ in MUSE. GLUCOSE utilises much less BECCS, about $0.2 \mathrm{Gt} \mathrm{CO}_{2} / \mathrm{yr}$ removal, but brings in DACCS, at about $0.7 \mathrm{Gt} \mathrm{CO}_{2} / \mathrm{yr}$. Note that the relatively high removal by BECCS is accompanied by relatively high fossil CCS, e.g. $4 \mathrm{Gt} \mathrm{CO}_{2} / \mathrm{yr}$ in TIAM-UCL by 2050, highlighting important investments in CCS capacity are needed both for mitigation and removal of $\mathrm{CO}_{2}$ emissions. 
bioenergy as a decarbonisation pathway (outside of power generation), consuming almost $300 \mathrm{EJ}$ by 2050, which is approximately a factor of 3 higher than TIAM-UCL, and towards the medium to low agreement threshold for what might consistute sustainable levels (Creutzig et al., 2015). TIAM-Grantham has conservative growth in electricity in the first half of the century, with stronger decarbonization in the second half of the century through CDR technologies, including BECCS and DACCS.

While there is considerable variation across models, in most cases signficant growth in electricity supply is required for decarbonising other sectors. The challenge is therefore not only to move away from fossil generation but dramatically increase the size of the electricity generation sector.

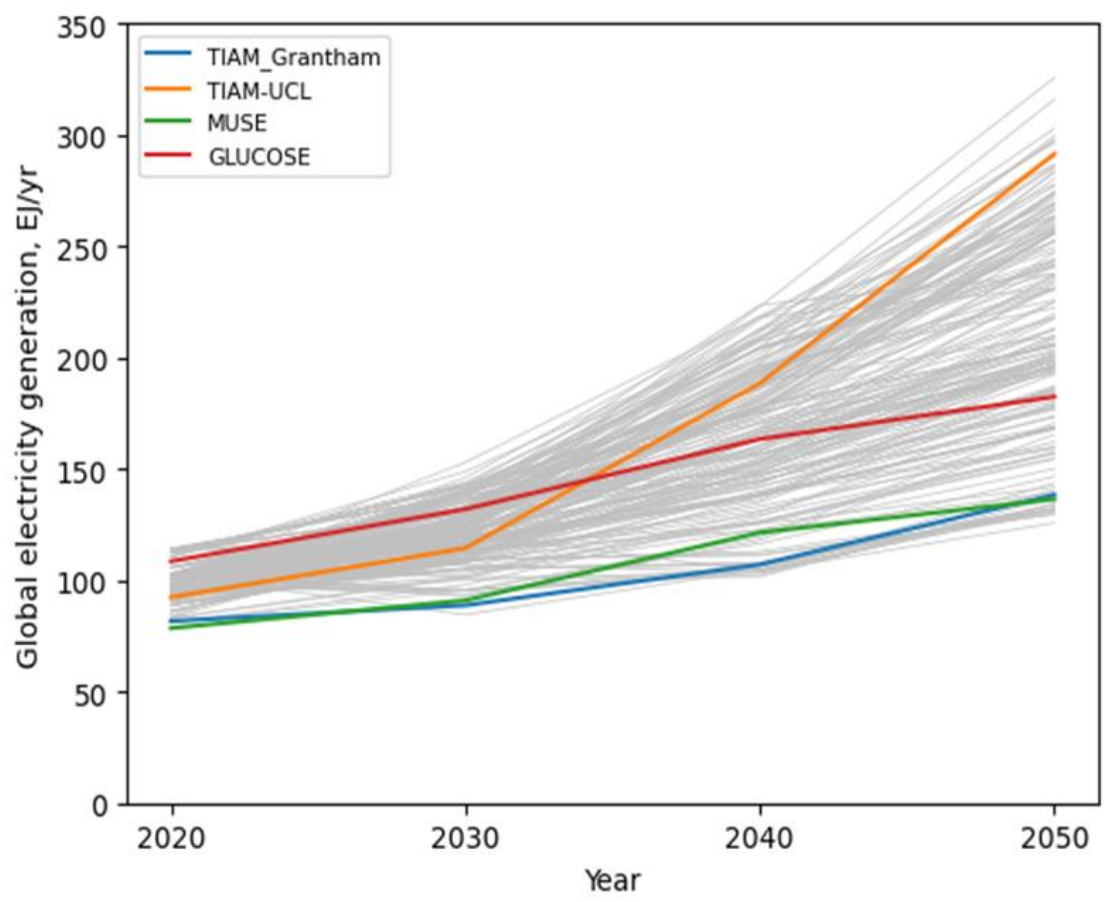

Figure 2. Global electricity generation for selected models for a $1.75^{\circ} \mathrm{C}$ target compared to SR1.5 scenario ensemble, 2020-50. Differences around the 2020 level reflect that this is a modelled period. IEA (IEA, 2020) reports the generation level at 97 EJ in 2019.

This is a large scale challenge, as low carbon generation currently only accounts for $37 \%$ (renewable generation share at $27 \%$, of which solar and wind account for $8 \%$ ) (IEA, 2020), while unabated coal is the single largest source of generation, accounting for around $37 \%$ of total generation. The modelling here shows how this share decreases over time, both under current NDC pledges and Paris aligned targets (Figure 3). Under the $1.75^{\circ} \mathrm{C}$ case, all models estimate that coal generation will need to drop below $5 \%$ in 2050. The shape of this decline is similar across most models, with an unabated coal share of $18-25 \%$ in 2030 , down to under $10 \%$ by 2040 . This requires that existing capacity is either decomissioned or utilised at much lower load factors. The exception in the ensemble is the TIAM-Grantham scenario which has an precipitous decline between 2020 and 2030, with only a 5\% share by 2030 and near zero by 2040 .

While the $1.75^{\circ} \mathrm{C}$ case sees a more rapid decline in the role for unabated coal, the NDC case also sees coal generation reduce relatively quickly. This is driven by country pledges but also the economics of renewables, which are already at lower costs than coal in many regions (even before accounting for externalities associated with $\mathrm{CO}_{2}$ and air quality pollutants). However, these rates of reduction are insufficient to meet Parisaligned targets. 


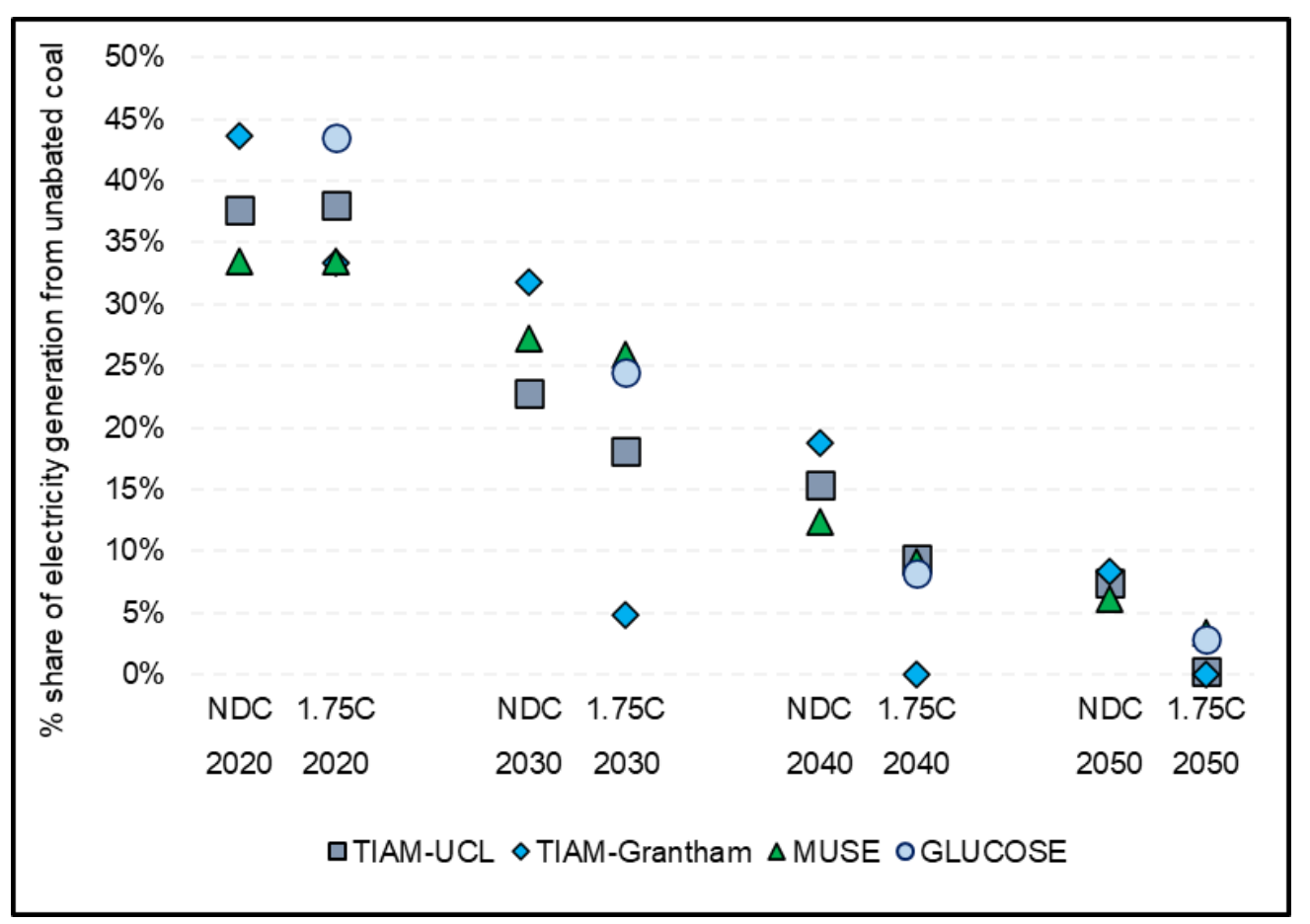

Figure 3. Global unabated coal generation as share of total generation for NDC and $1.75^{\circ} \mathrm{C}$ scenarios, 2020-50. Differences around the 2020 level reflect that this is a modelled period; hence the variation between models. Another reason is the inclusion or not of own producers of electricity, particularly in the industrial sector. IEA (IEA, 2020) reports the coal share at $37 \%$ in 2019.

The rapid transition envisaged in these scenarios means that investments today in unabated coal would not recover their full economic benefits, running at either much lower load factors or not at all in coming decades. It also suggests that net capacity additions will need to start to decrease, a decline that has been observed since 2011 (with the exception of 2015 and 2019) (Shearer et al., 2020). The decline in capacity in the modelled pathways from 2020 onwards is shown in Figure C1 in Appendix C. In 2020 , capacity additions (absolute, not net) were at around $60 \mathrm{GW}$ reducing to $20 \mathrm{GW}$ in 2030 (based on the TIAM-UCL $1.75^{\circ} \mathrm{C}$ scenario). Post-2030, there was no new capacity added, and hence the strong decline post-2030 in global installed capacity.

The stringency of the climate target and the cost-competitiveness of renewables means that installed coal capacity will have to be run at increasingly low load factors, or be fully decommissioned. For example, under the $1.75^{\circ} \mathrm{C}$ case, installed capacity in 2040 is around $1400 \mathrm{GW}$ in MUSE and TIAM-UCL (still above the 2000 level of $1000 \mathrm{GW}$ ), but only outputs at a load factor that is at $50-65 \%$ of the level observed in 2020. In 2050, for the remaining $500 \mathrm{GW}$ in TIAM-UCL, this drops to an average per unit capacity output level at $10 \%$ of the 2020 level, with an average load factor of around $8 \%$. This does not mean that the remaining fleet will all be operating at $8 \%$, but that many will be decomissioned and and a small percentage operated at higher load factors. GLUCOSE and MUSE show similar capacity of unabated coal in 2050, around $700 \mathrm{GW}$, with higher load factors at between 30 and $40 \%$ of the level observed in 2020 .

Figure 4 highlights the particularly high dependency on coal generation in the Asia region, particularly China and India, but also other parts of South East Asia (represented by the Higher Coal Dependent (HCD) group). Under NDCs, the reduction in coal generation is already large by 2030, around a 15-25\% drop from 2020 levels. By 2050, it is at around a third of 2020 levels, reflecting a shift towards cheap renewables even where stronger policy is absent. Under a $1.75^{\circ} \mathrm{C}$ case, unabated coal generation has all but disappeared by 2050. A recent paper has highlighted the potential for China to transition away from coal by rapidly remove poor performing plants and reducing utilisation of other plants over a 20-30 period (Cui et al., 2021), in a similar phase out as shown by this modelling analysis. In 2030, the level for TIAM-Grantham differs significantly from the other models, at around $5 \mathrm{EJ}$, illustrating a cost-optimal solution that is not limited by considerations of feasibility based on historical transitions. 
While unabated coal generation leaves the system, the question is whether there is a role for coal CCS? In general, most of the models do not suggest a signficant role, primarily due to the residual emissions not captured, and which constitutes a large source in a near zero emission energy system. The exception is the MUSE model, which builds out over $1000 \mathrm{GW}$ of coal CCS by 2050, offsetting the residual emissions via carbon dioxide removal technologies.
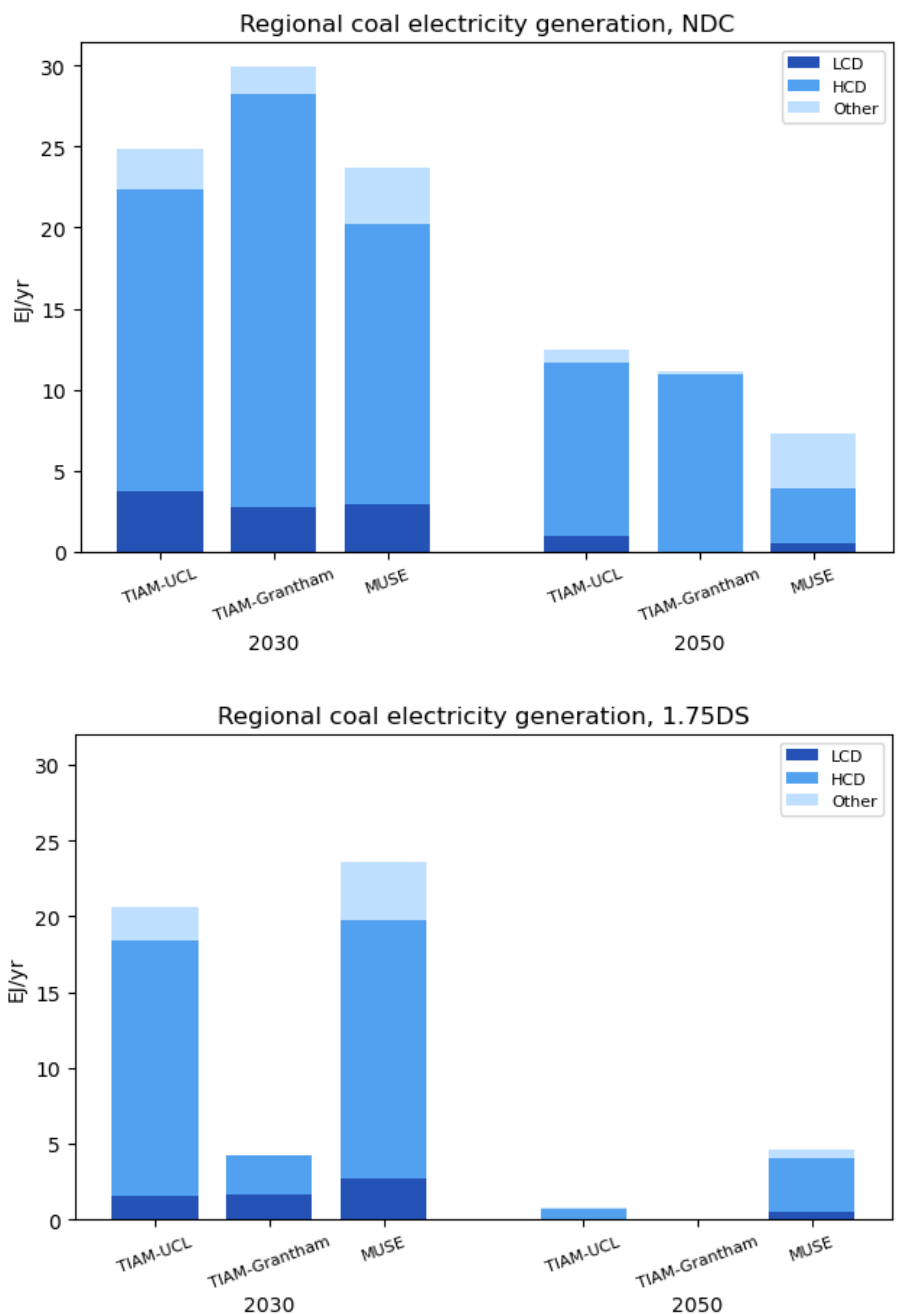

Figure 4. Regional generation from unabated coal under NDC (upper panel) and $1.75^{\circ} \mathrm{C}$ (lower panel) scenarios, 2020-50. Global generation in 2019 was in the region of $35 \mathrm{EJ}$. LCD = Lower Coal Dependent; HCD = Higher Coal Dependent.

The above scenarios make clear the need for a raft of policy measures and financial support that will be required to move away from coal generation, including long-lived assets that still have many years before their technical lifetime expires and planned new investments in coal capacity. The analysis also highlights the need for large scale investment in new generation to meet demand as coal plants are retired.

From the modelling, most of the investment in new capacity, both to replace coal, but also to increase the generating capacity of the system is renewable-based, particularly solar and wind. This is the case both for NDC and $1.75^{\circ} \mathrm{C}$ cases, with renewable generation being the most cost-effective generation source, even factoring in system integration costs. By 2050, both TIAM-UCL and TIAM-Grantham models have generation shares in excess of $75 \%$ in the $1.75^{\circ} \mathrm{C}$ case, with implied high levels of system storage (Figure 5). Due to the limited spatial and temporal resolution of these models, further testing of feasibility is likely to be needed for such systems, as highlighted by Brinkerink et al. (2021).

GLUCOSE and MUSE show more conservative uptakes of renewables, at just over $50 \%$ and $65 \%$ shares of generation, respectively. For MUSE, this reflects a relatively stronger 
focus on CCS and nuclear generation, as well as a higher dependence on hydrogen and biofuels in end use sectors. Despite the availability of cheap renewables, they are primarily constrained in MUSE by assumptions on renewable curtailment levels, on the power system reliability, which imposes a minimum share of generation coming from firm power plants, and on capacity factor by timeslice. In GLUCOSE, which has a less ambitious climate target, there is a stronger role biomass and gas generation, reducing the relative role for renewables (see Figure C3, Appendix C).

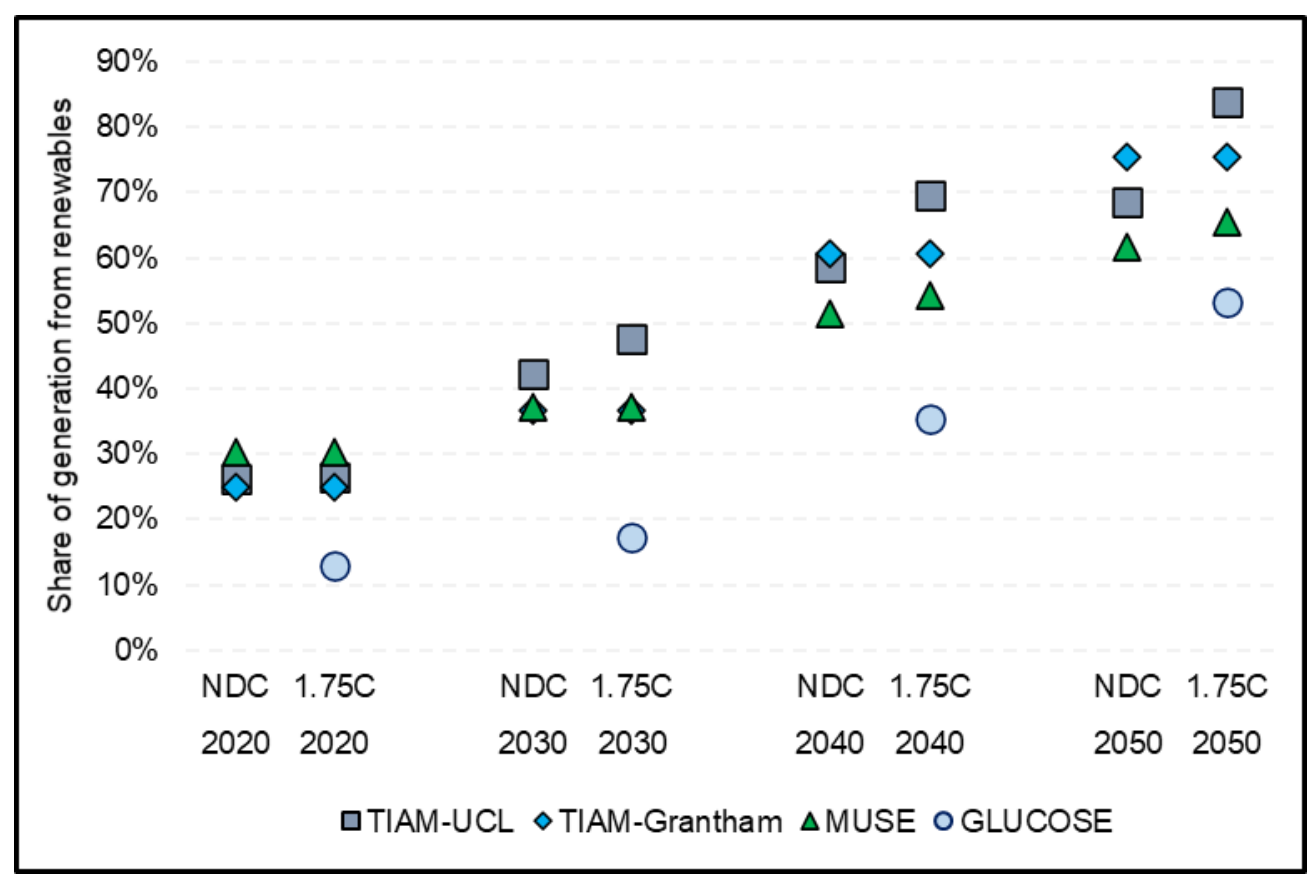

Figure 5. Shares of renewables (excluding bioenergy) as a percentage of total global generation, 2020-50. Differences around the 2020 level reflect that this is a modelled period. IEA (2020) reports the share of renewables (excluding bioenergy) to be $27 \%$ in 2019 .

The robust growth in installed capacity of renewables in TIAM-UCL in the $1.75^{\circ} \mathrm{C}$ case is largely driven by solar (18 TW), with wind contributing 10 TW (Figure C2, Appendix C). This suggests continued strong growth post 2040, with no significant decline in solar growth rates, or prospect of seeing 'saturation' of this technology. To put this level into context, total global capacity is at 7.5 TW, with all renewables at 2.7 TW. Of course, a renewables-based system will have an overall higher capacity due to the variable nature of solar and wind resources.

This scenario, while appearing an outlier relative to other models in this study, represents a high electrification outlook that provides the basis for deep end use sector decarbonisation. The 2050 level is high relative to recent analysis by IRENA (2020c), which put solar and wind capacity at $\sim 17$ TW; however, many other analyses show even more optimistic outlooks (Jaxa-Rozen and Trutnevyte, 2021), and some consider many scenarios to underestimate renewable generation potential (Victoria et al., 2021; Xiao et al., 2021). The current high growth rates of solar and its continuing cost reductions make determining longer term growth challenging.

The other models in the analysis put non-bioenergy renewables capacity at around 10 TW, with limited difference between 1.75 and NDC cases (for MUSE and TIAMGrantham). This suggests that the more rapid decarbonisation under $1.75^{\circ} \mathrm{C}$ case in these models is largely via other low carbon energy vectors, such as hydrogen and bioenergy and CDR technologies, DACCS and BECCS (as described above). 

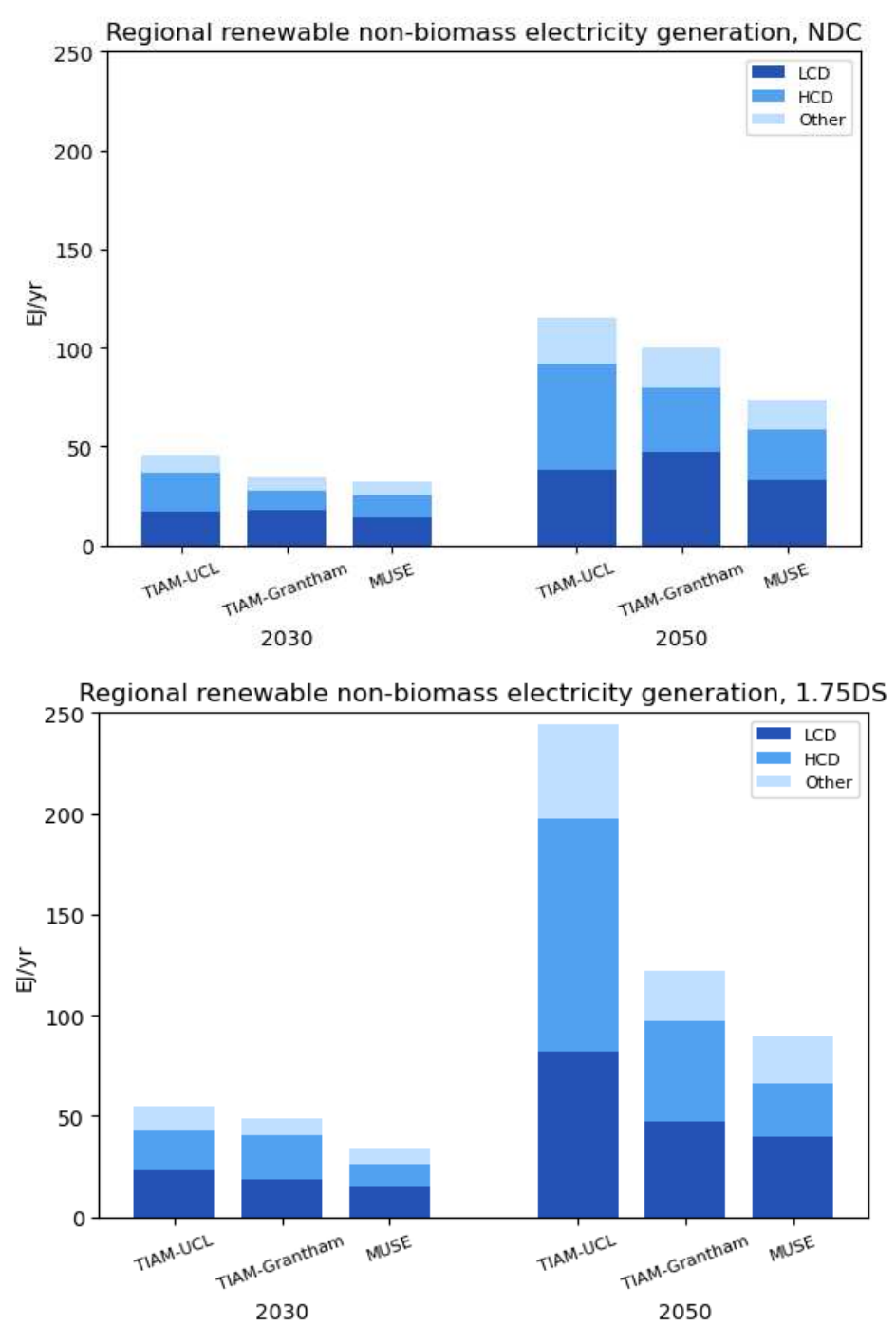

Figure 6. Regional generation from non-bioenergy renewables under NDC (upper panel) and $1.75^{\circ} \mathrm{C}$ (lower panel) scenarios, 2020-50. Global non-bioenergy renewable generation in 2019 was in the region of 23 EJ. LCD = Lower Coal Dependent; HCD = Higher Coal Dependent.

The growth in non-bioenergy renewables is strong across all regions, given the importance of electrification as a universal strategy (Figure 6). The very high level of generation in 2050 in TIAM-UCL is highlighted in the $1.75^{\circ} \mathrm{C}$ case. It is also interesting to note the relatively strong growth in the NDC case, from 2030 to 2050, as highlighted earlier in this section. This reflects their cost competitiveness relative to fossil fuel generation.

The contribution of electricity to different end use sectors in 2050 (relative to IEA 2019 levels) highlights what sectors see growth in electricity use (Figure 7). All models except MUSE show strong growth in electricity use in buildings. For industry, both TIAM-UCL and TIAM-Grantham see increases under the $1.75^{\circ} \mathrm{C}$ case, althought this is not observed for MUSE and GLUCOSE. Most of the growth for MUSE is in the transport sector. For those models that include both NDC and $1.75^{\circ} \mathrm{C}$ scenarios, it is only TIAM-UCL that show a strong variation in overall consumption; for MUSE this reflects that the NDC is also relatively ambitious, so does not differ greatly from the $1.75^{\circ} \mathrm{C}$ results. 


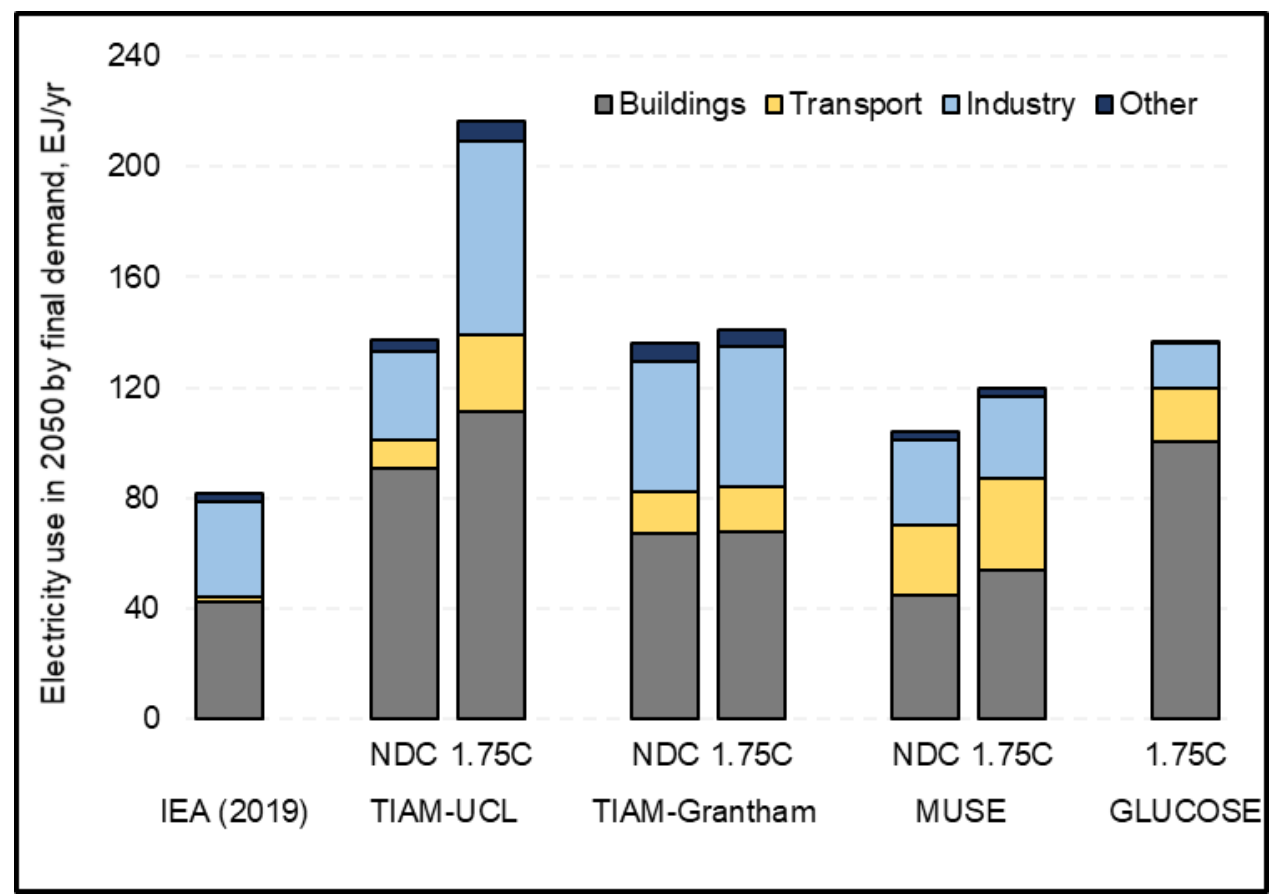

Figure 7. Electricity consumption by end use sector in 2050 , under NDC and $1.75^{\circ} \mathrm{C}$ cases

The global analyses highlights that while coal phase out is a an important precursor to Paris alinged decarbonisation, there are a range of different pathways. It highlights pathways contingent on large scale renewable deployment (TIAM-UCL), high levels of bioenergy resource availability (MUSE) and strong reliance on post-2050 CDR (TIAMGrantham). All profoundly shape the future pathways towards a low carbon economy. Further work also needs to be undertaken to explore how these pathways can be realised, in terms of political economy factors in different regions and techno-economic feasibility, as is discussed in the next section.

\section{Regional grids and coal phase out}

The global modelling described in the previous section has highlighted the crucial role that renewable energy sources will need to play to displace coal generation and to fully decarbonise the electricity supply. However, there are considerable challenges with a one-for-one replacement, due to the unpredictable nature of solar and wind renewable energy, as well as the time of generation. This is especially the case for solar, where peak generation is often in the middle of the day while peak demand is usually in the early evening. Proposed solutions to this challenge generally fall into two categories: utilizing energy storage to shift the midday generation to the evening peak, or utilizing transmission lines to connect midday solar generation in one location with evening peak demand in another. This second approach has been proposed as a way to enable a shift away from fossil generation to renewable generation for India by building a transmission interconnection from the Gulf Cooperation Council (GCC) region.

To assess the role regional grids may play, this part of the analysis focuses on the regional case study of India and the GCC region. The OSeMOSYS Global model is first used to evaluate the investment potential of a transmission line between Oman and Western India to reduce coal reliance and increase renewable energy penetration. The operational performance of the resulting system is assessed with the PLEXOS-World model. For information on both models, see Appendix A. Given the time difference between the GCC region and India, an interconnector can allow India to take advantage of solar power generation in the GCC region for a few hours after the sun has set in India (and export during seasonal periods of high RE generation). This in turn can lead to a higher share of renewable energy penetration in the electricity generation mix and a phase out of coal power generation. The analysis aims to identify conditions under which a GCC-India interconnector is techno-economically favourable. 
Using the OSeMOSYS Global model generator (Shivakumar et al., 2021), an energy system model that includes the six countries of the GCC region and India was constructed. Latin Hypercube sampling was used to explore the impact of different carbon emissions costs, fuel costs and transmission line costs on the development of the transmission interconnector. Twenty scenarios were constructed showing a range of capacity expansion mixes by 2050 . The model runs are characterised by a wide range of renewable deployment from around $330 \mathrm{GW}$ to $1800 \mathrm{GW}$. This picture is also reflected in the global IAMs, as shown in Figure C4 (Appendix C). Shares of coal power generation range from between $10-50 \%$ (Figure 8 ). The shares of hydro and nuclear power generation remain consistent across the model runs, while gas power generation varies based on the relative share of solar and wind. It is important to note that the demands and renewable profiles are the same for all scenarios; the reason that some scenarios have a much higher capacity is because of the lower capacity factor of solar and wind power plants relative to coal.

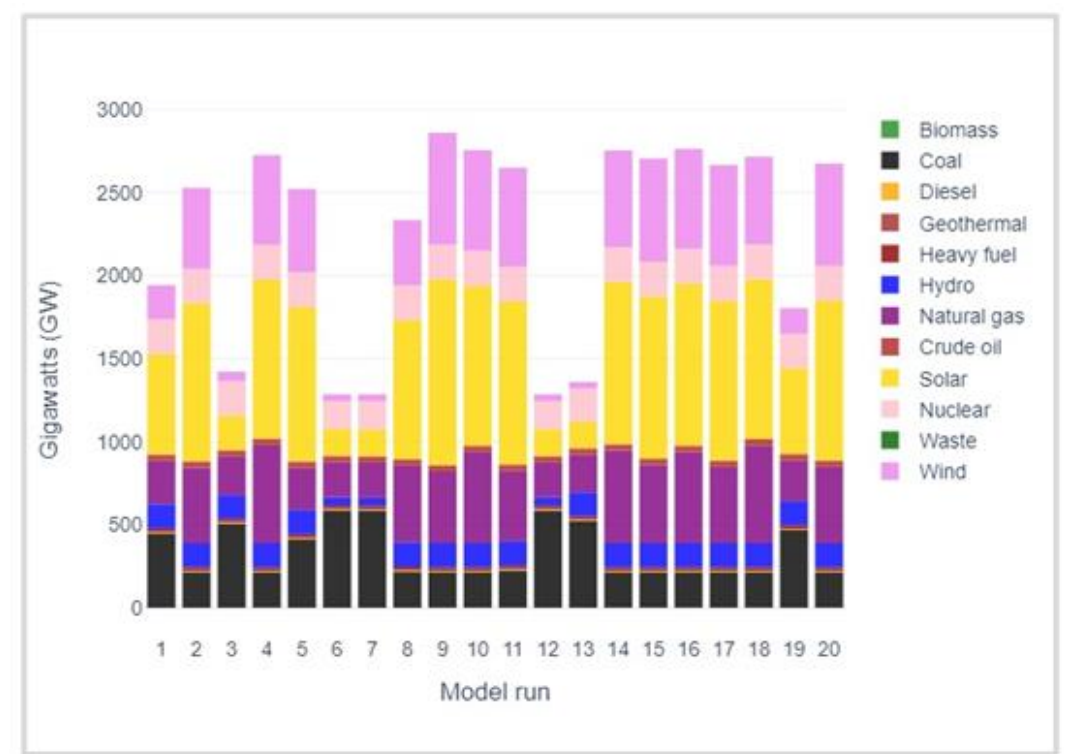

Figure 8. Power generation capacity mix across $\mathbf{2 0}$ scenarios run in the OSeMOSYS Global model for the GCC-India region, 2050. The capacity mix from the global IAMs for India in 2050 can be found in Appendix C.

The GCC-India interconnector is allowed to begin operating from 2028 onwards with a maximum increase of $5 \mathrm{GW}$ every five years, reaching a total allowable capacity of 25 GW by 2050. As shown in Figure 9, the interconnector is chosen as part of a cost-optimal solution in 15 of the 20 scenarios. Within these 15 scenarios where the interconnector is built, it reaches its maximum permitted capacity of $25 \mathrm{GW}$ in 14 of them. The build rate varies significantly across the cases and depends on a range of parameters including interconnector cost, carbon tax, solar-PV cost, and fossil fuel prices. 


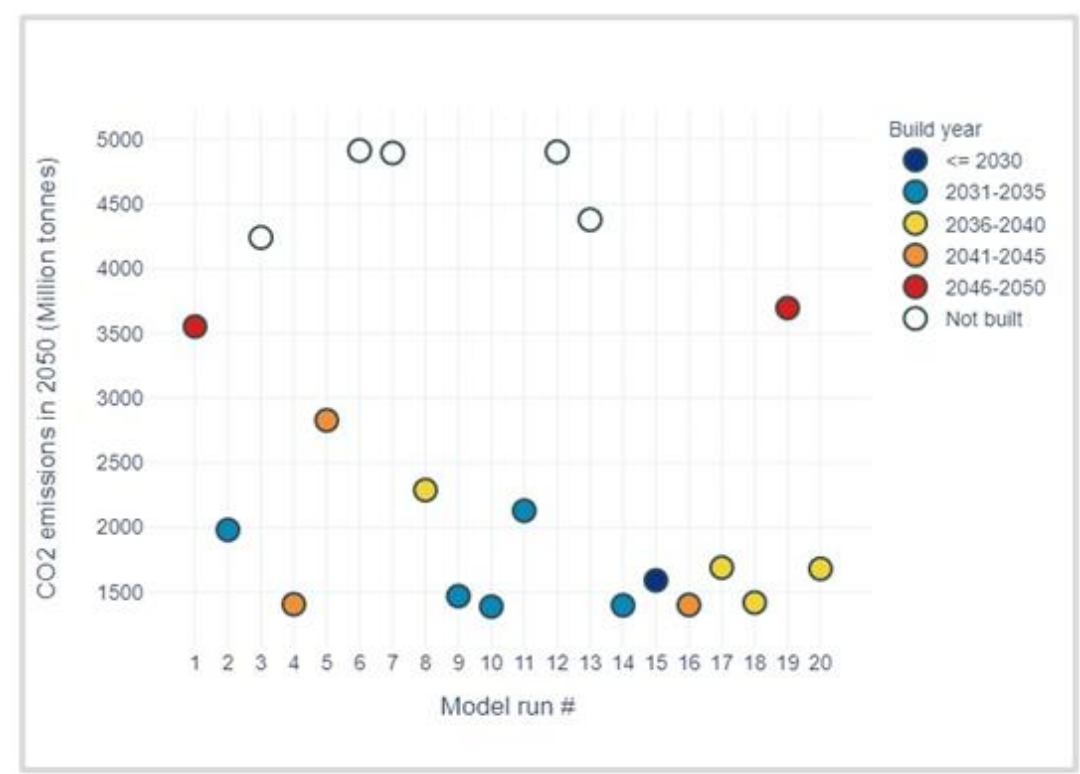

Figure 9. $\mathrm{CO}_{2}$ emissions and interconnector build year across 20 scenarios, 2028-50

PLEXOS-World is used to simulate the operation of the regional GCC-India power system, accounting for important technical details for conventional power plants such as start costs, ramp rates, efficiencies, and emissions. These details are important when considering the role of variable renewables such as wind and solar in future power systems as large conventional power stations like coal and gas can limit the ability of the power system to absorb high levels of renewables. PLEXOS-World can ensure the technical robustness and reliability of the resulting power system from the GCC-India OSeMOSYS Global model. This is important because not only must power systems decarbonise but they must also adhere to strict operational rules to ensure that the supply of electricity is adequate, reliable, and resilient.

The PLEXOS-World model is initialized with data from the GCC-India OSeMOSYS Global model which includes power plant and renewable portfolios, fuel prices, annual demand, and future interconnector capacities. Results from five different OSeMOSYS Global scenarios are assessed capturing a range of different generator portfolios and built interconnector capacities (scenarios 1,2,5,7,15). The OSeMOSYS Global scenario data set is expanded and downscaled to high temporal resolution ( 1 hour intervals) using techniques and methods as described in Brinkerink et al. (2021). PLEXOS-World simulates the year using mixed integer optimisation techniques which ensure that all technical characteristics of conventional power stations are enforced. The results of the PLEXOS-World modelling include generation levels by plant type, emissions, costs, electricity prices, and detailed interconnector flows from one region to another.

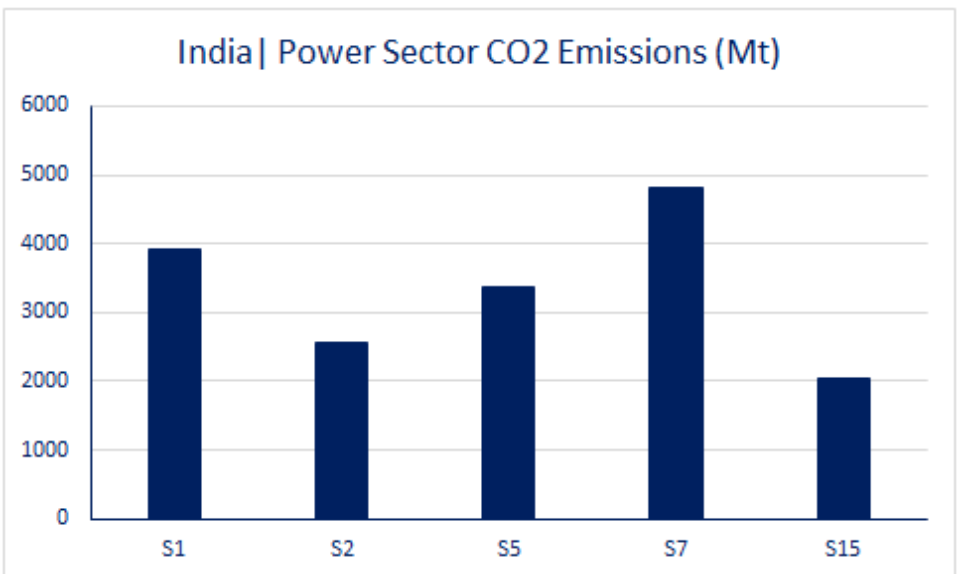

Figure 10. Power sector $\mathrm{CO}_{2}$ emissions in India for five selected scenarios, 2050 
Figure 10 shows that the lowest $\mathrm{CO}_{2}$ emissions in India are achieved in scenario 15 reflecting a higher level of renewable generation and lower coal fired generation, and therefore provides a focus in the rest of this section. In this scenario approximately one quarter of India's electricity demand is provided by wind and solar generation. The solarPV generation and export from Oman to India through the GCC-India interconnector reflects approximately $2 \%$ of India's annual generation and displaces coal generation avoiding $125 \mathrm{Mt}$ of $\mathrm{CO}_{2}$ in 2050.

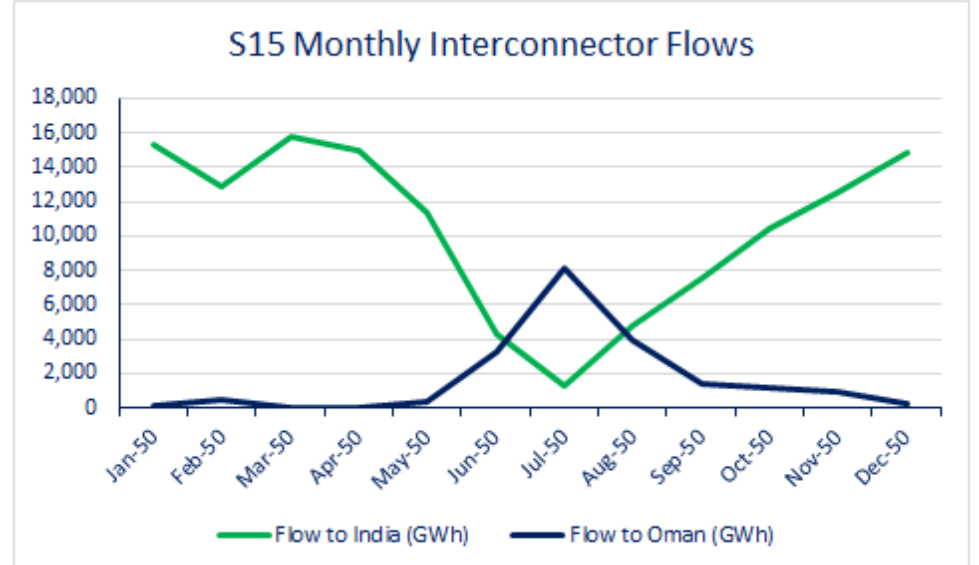

Figure 11. Monthly interconnector flow for the GCC-India scenario 15, 2050

An interesting element in bulk interconnector flow for the GCC-India interconnector for scenario 15 is the reversal of flows as shown in Figure 11 in the month of July, as this coincides with peak wind generation during India's monsoon period as shown in Figure 12 , which leads to net export of generation. Also, during these months coal generation in India is reduced but excess generation of renewables can be exported rather than curtailed. Periods of very high renewable generation and interaction with conventional plants such as coal and nuclear warrant closer investigation.

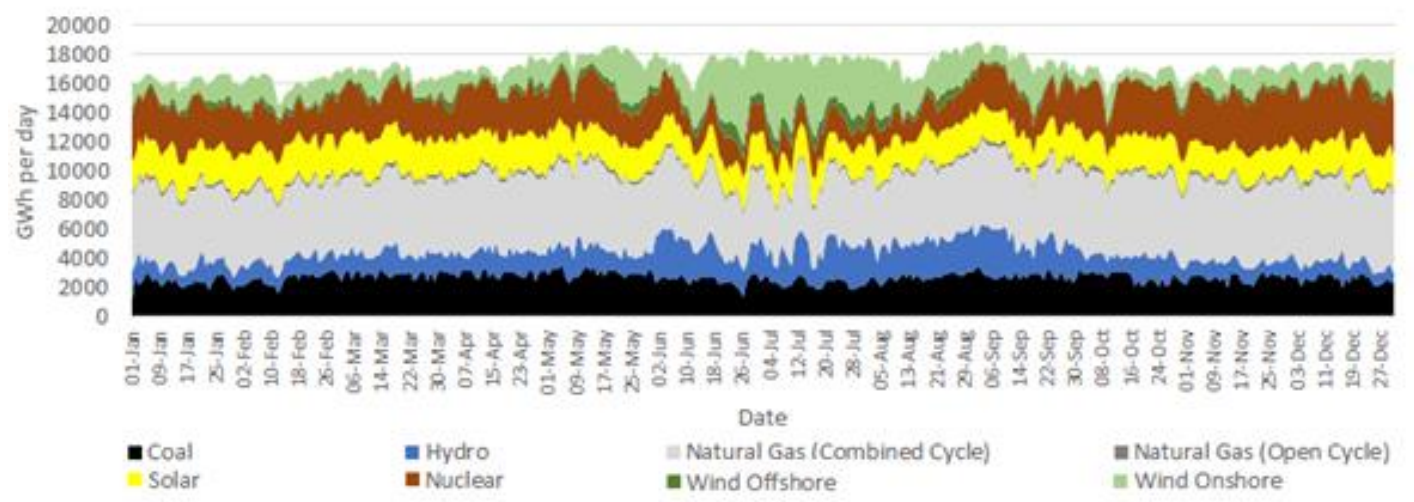

Figure 12. Daily generation by fuel in India for scenario 15, 2050

Looking more closely at regional electricity flows on both sides of the GCC-India interconnector in Figure 13, surplus solar generation in Oman is mostly exported to India due to the cost-efficiency of displacing coal-based generation with lower supply inwards to other countries within the GCC region. Within the GCC region large net flows can be identified from the United Arab Emirates to central Saudi Arabia and from central Saudi Arabia both westwards as well as up north to Kuwait. The southern part of India has vast hydro, wind, and solar resources and acts as the main exporting region within India. The east of India makes consistent use of electricity imports from all parts of the country due to its relative lower availability of efficient renewable resources. 
Bi-Directional Interconnector Flows S15 2050

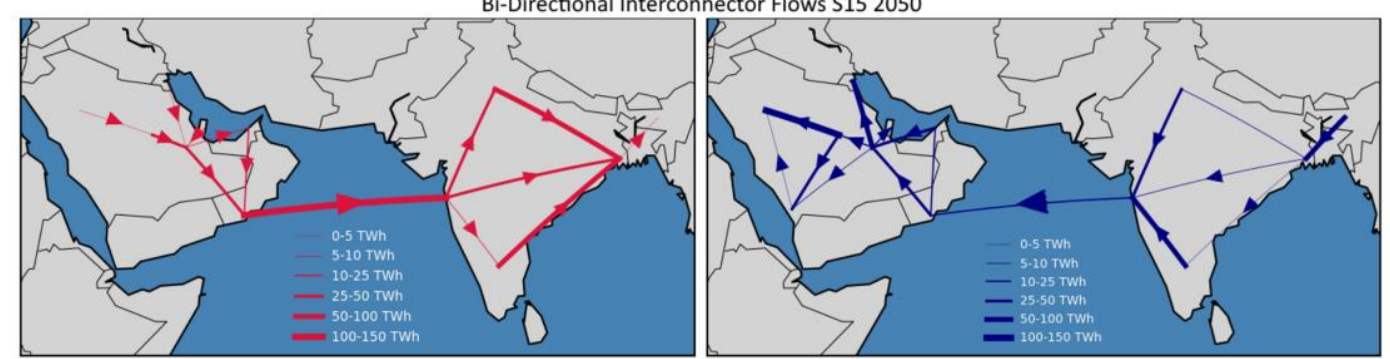

Figure 13. Bi-directional interconnector flows for scenario 15, 2050

Overall this case study shows the benefit of regionally-interconnected grids in facilitating the transition away from coal and supporting the higher uptake of renewables. Not only does the regional integration lead to overall lower $\mathrm{CO}_{2}$ emissions, it also has associated benefits such as reduced curtailment of renewables, lower need for domestic generator reserves and an overall higher system adequacy. A useful next phase of this assessment of the benefits of regionally-interconnected grids would be to extend by evaluating a higher interconnection capacity and a larger regional area (e.g. the whole of Africa, Middle-East and Asia). A stronger emphasis on the overall welfare benefits of regional integration as well as an assessment of the trade-offs with other flexibility providers such as electricity storage should be a focus.

\section{Conclusions}

This study highlights the need for rapid scaling of renewable generation investment and in turn the phase out of coal generation plants. If existing coal assets and those under construction where to be fully utilised over their lifetime, the objectives of the Paris Agreement would not be met. Therefore, policies that both incentivise renewable deployment and their system integration and which force early retirement of coal plants and disincentivise any new investment will be crucial.

The global IAM analysis provides insights on the scale of the challenge, and the implications for different regions, in order to have a chance of achieving global climate goals. The challenge is huge; countries not yet in the PPCA, and some distance from a coal phase out strategy, will need to be persuaded that resilient systems can be built on the back of renewables, which are subject to the challenge of intermittency. There will also need to be financial support for decommissioning recently built assets. While a range of countries have made the transition away from coal dependency, none have been at the scale of large economies such as China and India.

A key part of facilitating the transition in high coal dependent regions towards renewable based systems could be through regionally connected grids, allowing for the transmission and supply of electricity from high renewable resource regions to large demand centres previously reliant on coal power. In this study, the case for an interconnection between India and the Gulf region was explored, showing that integration of renewables in some cases leads to lower use of coal power plants without necessarily having to force it out through top-down climate policies. In other words, the economics of such a strategy often make sense.

More focused regional and country analyses, as undertaken in the Gulf-India study, will be important for providing more granular representation of systems, to pick up specific regional characteristics and explore tailored solutions that will enable the transitions away from coal generation towards systems built on renewables and other forms of low carbon generation. This should include oportunities for regionally interconnected grids as part of techno-economic analyses of system design, but also the political feasibility of coal phase out, and policy packages that will overcome such barriers.

While an enormous challenge, the co-benefits of reducing coal use are significant, notably on air pollution reduction and the benefits to health (Markandya et al., 2018). The investment opportunity to build out a new generation system holds large scale benefits for manufacturing and energy sectors and the jobs that will be generated (IRENA, 2020c). The generation sector in capacity terms will need to be more than doubled, while replacing much of the existing capacity with low carbon generation. The ultimate size of the generation system will be dependent on the role of electricity as an 
energy vector for decarbonisation; as some IAM models have shown, hydrogen and bioenergy, including with CCS, offer potential pathways that might reduce reliance on renewable electricity. However, such pathway also have significant technical challenges to scale e.g. sustainability of bioenergy use, commercialisation of $\mathrm{CCS}, \mathrm{H}_{2}$ pathways.

\section{Declarations}

\section{Data availability}

All results presented in this report can be found at https://doi.org/10.5281/zenodo.4646917, and are available under license CC BY 4.0 (https://creativecommons.org/licenses/by/4.0/).

\section{Author contributions}

Steve Pye: research lead, conceptualisation, analysis of IAM results, report writing lead; Isabela Butnar: TIAM-UCL modelling, analysis of IAM results, report writing; Shivika Mittal: TIAM-Grantham modelling, report writing; Sara Giarola: MUSE modelling, report writing; Adam Hawkes: report review; Agnese Beltramo: GLUCOSE modelling, report writing; Will Usher: GLUCOSE modelling; Maarten Brinkerink: PLEXOS World modelling, report writing, conceptualisation; Paul Deane: conceptualisation, PLEXOS World modelling; Liliana Benitez: PLEXOS World modelling; Taco Niet: Osemosys Global modelling, report writing; Abhishek Shivakumar: Osemosys Global modelling, report writing.

\section{Acknowledgements}

The authoring team acknowledges the support of the Climate Compatible Growth Program (\#CCG) of the UK's Foreign Development and Commonwealth Office (FCDO). The views expressed in this paper do not necessarily reflect the UK government's official policies.

\section{Conflicts of interest}

The authors declare no conflicts of interest.

\section{References}

Alexander, P., Brown, C., Arneth, A., Finnigan, J., Moran, D., Rounsevell, M.D.A., 2017. Losses, inefficiencies and waste in the global food system. Agric. Syst. 153, 190200. https://doi.org/10.1016/j.agsy.2017.01.014

Allwood, J.M., Cullen, J.M., Carruth, M.A., Cooper, D.R., McBrien, M., Milford, R.L., Moynihan, M.C., Patel, A.C.H., 2012. Sustainable materials: with both eyes open. Citeseer.

Bauer, N., McGlade, C., Hilaire, J., Ekins, P., 2018. Divestment prevails over the green paradox when anticipating strong future climate policies. Nat. Clim. Chang. https://doi.org/10.1038/s41558-017-0053-1

Brinkerink, M., Deane, P., 2020. PLEXOS-World 2015. https://doi.org/doi:10.7910/DVN/CBYXBY

Brinkerink, Maarten, Gallachóir, B.Ó., Deane, P., 2021. Building and Calibrating a Country-Level Detailed Global Electricity Model Based on Public Data. Energy $\begin{array}{lll}\text { Strateg. } & \text { Rev. } & 33,\end{array}$ https://doi.org/https://doi.org/10.1016/j.esr.2020.100592

Brinkerink, M, Zakeri, B., Huppmann, D., Glynn, J., Ó Gallachóir, B., Deane, P., 2021. Assessing global climate change mitigation scenarios from a power system 
perspective using a novel multi-model framework. Environ. Model. Softw.

Creutzig, F., Ravindranath, N.H., Berndes, G., Bolwig, S., Bright, R., Cherubini, F., Chum, H., Corbera, E., Delucchi, M., Faaij, A., Fargione, J., Haberl, H., Heath, G., Lucon, O., Plevin, R., Popp, A., Robledo-Abad, C., Rose, S., Smith, P., Stromman, A., Suh, S., Masera, O., 2015. Bioenergy and climate change mitigation: An assessment. GCB Bioenergy 7, 916-944. https://doi.org/10.1111/gcbb.12205

Cui, R.Y., Hultman, N., Cui, D., McJeon, H., Yu, S., Edwards, M.R., Sen, A., Song, K., Bowman, C., Clarke, L., Kang, J., Lou, J., Yang, F., Yuan, J., Zhang, W., Zhu, M., 2021. A plant-by-plant strategy for high-ambition coal power phaseout in China. Nat. Commun. 12, 1468. https://doi.org/10.1038/s41467-021-21786-0

Dorband, I.I., Jakob, M., Steckel, J.C., 2020. Unraveling the political economy of coal: Insights from Vietnam. Energy Policy 147, 111860.

Fricko, O., Havlik, P., Rogelj, J., Klimont, Z., Gusti, M., Johnson, N., Kolp, P., Strubegger, M., Valin, H., Amann, M., Ermolieva, T., Forsell, N., Herrero, M., Heyes, C., Kindermann, G., Krey, V., McCollum, D.L., Obersteiner, M., Pachauri, S., Rao, S., Schmid, E., Schoepp, W., Riahi, K., 2017. The marker quantification of the Shared Socioeconomic Pathway 2: A middle-of-the-road scenario for the 21st century. Glob. Environ. A A 42, 251-267. https://doi.org/10.1016/j.gloenvcha.2016.06.004

Giarola, S., Molar-Cruz, A., Vaillancourt, K., Bahn, O., Sarmiento, L., Hawkes, A., Brown, M., 2021. The role of energy storage in the uptake of renewable energy: A model comparison approach. Energy Policy 151, 112159. https://doi.org/https://doi.org/10.1016/j.enpol.2021.112159

Huppmann, D., Rogelj, J., Kriegler, E., Krey, V., Riahi, K., 2018. A new scenario resource for integrated $1.5{ }^{\circ} \mathrm{C}$ research. Nat. Clim. Chang. 8, 1027-1030. https://doi.org/10.1038/s41558-018-0317-4

IEA, 2020. World Energy Outlook 2020. International Energy Agency (IEA), Paris, France.

IEA, 2012. Energy technology perspectives 2012: Pathways to a clean energy system, Energy Technol. Perspect. 2012 Pathways to a Clean Energy Syst. International Energy Agency (IEA), Paris, France.

IRENA, 2020a. Renewable capacity highlights. International Renewable Energy Agency, Abu Dhabi.

IRENA, 2020b. Renewable Power Generation Costs in 2019. International Renewables Energy Agency, Abu Dhabi, UAE.

IRENA, 2020c. Global Renewables Outlook: Energy transformation 2050. International Renewables Energy Agency, Abu Dhabi.

Jaxa-Rozen, M., Trutnevyte, E., 2021. Sources of uncertainty in long-term global scenarios of solar photovoltaic technology. Nat. Clim. Chang. 11, 266-273. https://doi.org/10.1038/s41558-021-00998-8

Jewell, J., Vinichenko, V., Nacke, L., Cherp, A., 2019. Prospects for powering past coal. Nat. Clim. Chang. 9, 592-597. https://doi.org/10.1038/s41558-019-0509-6

Markandya, A., Sampedro, J., Smith, S.J., Van Dingenen, R., Pizarro-Irizar, C., Arto, I., González-Eguino, M., 2018. Health co-benefits from air pollution and mitigation costs of the Paris Agreement: a modelling study. Lancet Planet. Heal. 2, e126e133. https://doi.org/https://doi.org/10.1016/S2542-5196(18)30029-9

McCollum, D.L., Wilson, C., Bevione, M., Carrara, S., Edelenbosch, O.Y., Emmerling, J., Guivarch, C., Karkatsoulis, P., Keppo, I., Krey, V., Lin, Z., Broin, E., Paroussos, L., Pettifor, H., Ramea, K., Riahi, K., Sano, F., Rodriguez, B.S., van Vuuren, D.P., 2018. Interaction of consumer preferences and climate policies in the global transition to low-carbon vehicles. Nat. Energy 3, 664-673. https://doi.org/10.1038/s41560-018-0195-z

McGlade, C., Ekins, P., 2015. The geographical distribution of fossil fuels unused when limiting global warming to $2{ }^{\circ} \mathrm{C}$. Nature 517, 187-190. https://doi.org/https://doi.org/10.1038/nature14016

Pye, S., Bradley, S., Hughes, N., Price, J., Welsby, D., Ekins, P., 2020. An equitable 
redistribution of unburnable carbon. Nat. Commun. 11, 3968. https://doi.org/10.1038/s41467-020-17679-3

Realmonte, G., Drouet, L., Gambhir, A., Glynn, J., Hawkes, A., Köberle, A.C., Tavoni, M., 2019. An inter-model assessment of the role of direct air capture in deep mitigation pathways. Nat. Commun. https://doi.org/10.1038/s41467-019-108425

Rogelj, J., Shindell, D., Jiang, K., Fifita, S., Forster, P., Ginzburg, V., Handa, C., Kheshgi, H., Kobayashi, S., Kriegler, E., Mundaca, L., Séférian, R., Vilariño, M.V., 2018. Mitigation Pathways Compatible with $1.5^{\circ} \mathrm{C}$ in the Context of Sustainable Development, in: Global Warming of $1.5^{\circ} \mathrm{C}$. An IPCC Special Report on the Impacts of Global Warming of $1.5^{\circ} \mathrm{C}$ above Pre-Industrial Levels and Related Global Greenhouse Gas Emission Pathways.

Shearer, C., Myllyvirta, L., Yu, A., Aitken, G., Mathew-Shah, N., Dallos, G., Nace, T., 2020. Boom and bust 2020: Tracking the global coal plant pipeline. Global Energy Monitor, Sierra Club, Greenpeace International.

Shivakumar, A., Brinkerink, M., Niet, T., Usher, W., 2021. OSeMOSYS/osemosys_global: Development release for CCG.

Spencer, T., Colombier, M., Sartor, O., Garg, A., Tiwari, V., Burton, J., Caetano, T., Green, F., Teng, F., Wiseman, J., 2018. The $1.5^{\circ} \mathrm{C}$ target and coal sector transition: at the limits of societal feasibility. Clim. Policy 18, 335-351. https://doi.org/10.1080/14693062.2017.1386540

Tong, D., Zhang, Q., Zheng, Y., Caldeira, K., Shearer, C., Hong, C., Qin, Y., Davis, S.J., 2019. Committed emissions from existing energy infrastructure jeopardize $1.5^{\circ} \mathrm{C}$ climate target. Nature 572, 373-377. https://doi.org/10.1038/s41586-019-13643

United Nations, 2015. Adoption of the Paris Agreement, Conference of the Parties on its twenty-first session. https://doi.org/FCCC/CP/2015/L.9

United Nations, 2014. Prototype global sustainable development report. United Nations Department of Economic and Social Affairs, Division for Sustainable Development, New York.

van Vuuren, D.P., Riahi, K., Calvin, K., 2017. The Shared Socio-economic Pathways: Trajectories for human development and global environmental change. Glob. Environ. Chang. 42, 148-152. https://doi.org/10.1016/j.gloenvcha.2016.10.009

Victoria, M., Haegel, N., Peters, I.M., Sinton, R., Jäger-Waldau, A., del Cañizo, C., Breyer, C., Stocks, M., Blakers, A., Kaizuka, I., Komoto, K., Smets, A., 2021. Solar photovoltaics is ready to power a sustainable future. Joule. https://doi.org/https://doi.org/10.1016/j.joule.2021.03.005

Vivid Economics, 2021. Greenness of Stimulus Index. London, UK.

Vivid Economics, UCL Energy Institute, 2020. Unpacking leadership-driven global scenarios towards the Paris Agreement. London, UK.

Willett, W., Rockström, J., Loken, B., Springmann, M., Lang, T., Vermeulen, S., Garnett, T., Tilman, D., DeClerck, F., Wood, A., 2019. Food in the Anthropocene: the EATLancet Commission on healthy diets from sustainable food systems. Lancet 393, 447-492.

Xiao, M., Junne, T., Haas, J., Klein, M., 2021. Plummeting costs of renewables - Are energy scenarios lagging? Energy Strateg. Rev. 35, 100636. https://doi.org/https://doi.org/10.1016/j.esr.2021.100636 


\section{Appendices}

\section{Appendix A. Model descriptions}

Table 1. Global models involved in CCG scenario exercise

\begin{tabular}{|c|c|c|}
\hline $\begin{array}{l}\text { Model name } \\
\text { (key reference) }\end{array}$ & $\begin{array}{l}\text { Model } \\
\text { team }\end{array}$ & Model Description \\
\hline $\begin{array}{l}\text { PLEXOS-World } \\
\text { (Maarten } \\
\text { Brinkerink et al., } \\
2021 \text { ) }\end{array}$ & UCC & $\begin{array}{l}\text { This is a global hourly unit commitment and dispatch } \\
\text { electricity model capable of simulating the dispatch of over } \\
30,000 \text { existing power plants spread out over } 164 \text { countries } \\
\text { and } 258 \text { regions, all using public data. The model is calibrated } \\
\text { to } 2015 \text { data and all input are openly available and } \\
\text { adjustable. The model can also be linked to future energy } \\
\text { scenarios from IAMs or energy system models and detailed } \\
\text { hourly simulation of the power system can be undertaken. } \\
\text { Key strengths / focus: Power Systems Decarbonisation } \\
\text { Pathways, Flexibility, Interconnection. }\end{array}$ \\
\hline $\begin{array}{l}\text { TIAM-UCL (Bauer } \\
\text { et al., 2018; } \\
\text { McCollum et al., } \\
\text { 2018; McGlade } \\
\text { and Ekins, 2015; } \\
\text { Pye et al., 2020) }\end{array}$ & UCL & $\begin{array}{l}\text { The TIMES Integrated Assessment Model (IAM) at University } \\
\text { College London (TIAM-UCL) provides a } 16 \text { region } \\
\text { representation of the global energy system, capturing } \\
\text { primary energy sources from production through to their } \\
\text { conversion, their transport and distribution, and their } \\
\text { eventual use to meet energy demands across a range of } \\
\text { economic sectors. Using a scenario-based approach, the } \\
\text { evolution of the system over time to meet future energy } \\
\text { service demands can be simulated, driven by a least-cost } \\
\text { objective. } \\
\text { Key strengths / focus: fossil fuel transitions, CDR } \\
\text { assessment, transport futures, decarbonisation pathways }\end{array}$ \\
\hline $\begin{array}{l}\text { TIAM-Grantham } \\
\text { (Realmonte et al., } \\
\text { 2019) }\end{array}$ & IC & $\begin{array}{l}\text { TIAM-Grantham is a 15-region global integrated assessment } \\
\text { model underpinned by the technological expertise of Imperial } \\
\text { College London. It includes up to date representations of } \\
\text { resources, infrastructure and technology across the global } \\
\text { energy system. It has recently been re-calibrated to } \\
\text { accurately reflect all current climate policies and related } \\
\text { reference trajectories, and new mitigation measures from } \\
\text { DACC to detailed H2 systems representation. } \\
\text { Key strengths / focus: fossil fuel transitions, CDR } \\
\text { assessment, H2/electrification futures, decarbonisation } \\
\text { pathways }\end{array}$ \\
\hline $\begin{array}{l}\text { MUSE (Giarola et } \\
\text { al., 2021) }\end{array}$ & IC & $\begin{array}{l}\text { MUSE is a novel agent-based integrated assessment model, } \\
\text { designed to provide a counterpoint to contemporary analyses } \\
\text { of deep decarbonisation. It represents the decision making of } \\
\text { firms and consumers across the global energy system in } 28 \\
\text { regions, using a hybrid approach where each sector is an } \\
\text { agent-based model tailored and parameterised specifically } \\
\text { for that sector to reflect real-world decision making. It is a } \\
\text { bottom-up (i.e engineering detail), recursive dynamic, partial } \\
\text { equilibrium model, able to produce transition scenarios to } \\
2100 \text { and beyond. }\end{array}$ \\
\hline
\end{tabular}




\begin{tabular}{|c|c|c|}
\hline & & $\begin{array}{l}\text { Key strengths / focus: agent-based modelling, technology } \\
\text { assessment, H2/electrification futures, decarbonisation } \\
\text { pathways }\end{array}$ \\
\hline $\begin{array}{l}\text { GLUCOSE (United } \\
\text { Nations, 2014) }\end{array}$ & KTH & $\begin{array}{l}\text { GLUCOSE is a highly-aggregated one-region global } \\
\text { integrated assessment model developed using the Open } \\
\text { Source energy MOdelling SYStem (OSeMOSYS) and originally } \\
\text { based on the Climate, Land, Energy, Water strategy (CLEWs) } \\
\text { assessment framework. The model is divided in three } \\
\text { submodules, namely energy, land and food, and materials } \\
\text { module, interconnected through resource flows. The model } \\
\text { operates by computing the least-cost optimal solution for the } \\
\text { system to meet exogenously and endogenously defined } \\
\text { demands for energy, food and materials respectively. Thanks } \\
\text { to its highly aggregated structure, the model can be easily } \\
\text { modified to generate a wide range of scenarios and explore } \\
\text { policy alternatives for the sustainable management of } \\
\text { resources. } \\
\text { Key strengths / focus: integrated resource assessment, } \\
\text { cross-sectoral interlinkages, scenario exploration. }\end{array}$ \\
\hline $\begin{array}{l}\text { OSeMOSYS Global } \\
\text { (Shivakumar et } \\
\text { al., 2021) }\end{array}$ & $\begin{array}{l}\text { SFU, UN- } \\
\text { DESA, UCC }\end{array}$ & $\begin{array}{l}\text { OSeMOSYS Global is an open-source, open-data model } \\
\text { generator for creating global energy system models using the } \\
\text { PLEXOS-World datasets (Brinkerink and Deane, 2020) as a } \\
\text { baseline. The model generator is freely available, can be used } \\
\text { to create inter-connected energy systems models for both } \\
\text { the entire globe and for any geographically diverse subset of } \\
\text { the globe. Compared to other existing global models, } \\
\text { OSeMOSYS Global creates a full energy system } \\
\text { representation, allows for full user flexibility in determining } \\
\text { the time slice structure and geographic scope, and is built } \\
\text { using the fully open-source OSeMOSYS energy system } \\
\text { model. }\end{array}$ \\
\hline
\end{tabular}




\section{Appendix B. Modelling assumptions for IAMs}

\begin{tabular}{|c|c|c|c|c|}
\hline & TIAM-UCL & TIAM-Grantham & MUSE & OSeMOSYS Global \\
\hline \multirow[t]{2}{*}{ Drivers } & Consistent with SSP2 & Consistent with SSP2 & Consistent with SSP2 & Consistent with SSP2 \\
\hline & Consistent with SSP2 & Consistent with SSP2 & Consistent with SSP2 & Consistent with SSP2 \\
\hline \multirow[t]{3}{*}{$\begin{array}{l}\text { Climate con- } \\
\text { straints }\end{array}$} & $\begin{array}{l}1.75^{\circ} \mathrm{C} \text { in } 2100,66 \% / 50 \% \text { likeli- } \\
\text { hood }\end{array}$ & $\begin{array}{l}1.75^{\circ} \mathrm{C} \text { in } 2100,66 \% / 50 \% \\
\text { likelihood }\end{array}$ & $\begin{array}{l}1.75^{\circ} \mathrm{C} \text { in } 2100,66 \% / 50 \% \\
\text { likelihood }\end{array}$ & $\begin{array}{l}1.75^{\circ} \mathrm{C} \text { in } 2100 \text {, based on SSP2 RCP } 2.6 \\
\text { scenario GHG emissions trajectory }\end{array}$ \\
\hline & $\begin{array}{l}\text { Not more than } 1.8^{\circ} \mathrm{C} \text {, limiting } \\
\text { negative removal techs }\end{array}$ & & & ( \\
\hline & $800 \mathrm{GtCO}_{2}$ (from 2018 onwards) & $\begin{array}{l}800 \mathrm{GtCO}_{2} \text { (from } 2018 \text { on- } \\
\text { wards) }\end{array}$ & $\begin{array}{l}800 \mathrm{GtCO}_{2} \text { (from } 2018 \text { on- } \\
\text { wards) }\end{array}$ & $1400 \mathrm{GtCO}_{2}$ (from 2020 onwards) \\
\hline \multirow[t]{4}{*}{$\begin{array}{l}\text { Non-energy path- } \\
\text { ways }\end{array}$} & Consistent with RCP 2.6 & & & $\begin{array}{l}\text { Emissions: model output; agriculture } \\
\text { transformation processes based } \\
\text { on Alexander et al. (2017) }\end{array}$ \\
\hline & $\begin{array}{l}\text { Based on a MAgPIE } 2^{\circ} \mathrm{C} \text { scenario, } \\
66 \% \text { probability }\end{array}$ & & & $\begin{array}{l}\text { Emissions: model output; } \\
\text { Land use based on FAOSTAT and AQ- } \\
\text { UASTAT data }\end{array}$ \\
\hline & Consistent with RCP 2.6 & & & - \\
\hline & & & & $\begin{array}{l}\text { Emissions: model output; materials de- } \\
\text { mand reduced by changes in products } \\
\text { design, from } 2020 \text { till } 2050 \text { (based on } \\
\text { (Allwood et al., 2012)). }\end{array}$ \\
\hline
\end{tabular}

${ }^{3}$ Food and Agriculture Organisation statistics: http://www.fao.org/faostat/en/\#home and http://www.fao.org/aquastat/en/data-analysis/irrig-water-use/tables-references 


\begin{tabular}{|c|c|c|c|c|}
\hline $\begin{array}{l}\text { Resource as- } \\
\text { sumptions }\end{array}$ & $\begin{array}{l}\text { Limited to } 110 \mathrm{PJ} \text { per year from } \\
2050\end{array}$ & $\begin{array}{l}\text { Limited to } 100 \text { EJ per year } \\
\text { from } 2050 \text { at global level; } \\
\text { Regional constraints are also } \\
\text { included }\end{array}$ & Unconstrained & $\begin{array}{l}\text { Linked to biomass production from land } \\
\text { (forest, agriculture) }\end{array}$ \\
\hline & $\begin{array}{l}\text { Modelled in detail based } \\
\text { on McGlade and Ekins, 2015, } \\
\text { and Pye et al., } 2020\end{array}$ & & $\begin{array}{l}\text { Supply curve for all resources; } \\
\text { detailed modelling for gas }\end{array}$ & Based on (IEA, 2012) \\
\hline \multirow[t]{5}{*}{ Policies } & NDC & & NDC & $\begin{array}{l}\text { Based on current policies as define in } \\
\text { IEA ETP } 2012\end{array}$ \\
\hline & $\begin{array}{l}\text { High ambition countries, Aus- } \\
\text { tralia and New Zealand, Canada, } \\
\text { EU, Japan, South Korea, UK, } \\
\text { USA, reach net zero CO2 / } \\
\text { GHG by } 2050\end{array}$ & $\begin{array}{l}\text { Includes long-term ambitions } \\
\text { for Mexico, China, Japan, Eu- } \\
\text { rope, South Korea, South Af- } \\
\text { rica, United States, New Zea- } \\
\text { land }\end{array}$ & $\begin{array}{l}\text { Includes long-term ambitions } \\
\text { for Mexico, China, Japan, Eu- } \\
\text { rope, South Korea, South Af- } \\
\text { rica, United Stated }\end{array}$ & $\begin{array}{l}\text { Global GHG emission limit in line with } \\
\text { SSP2 RCP2.6 scenario }\end{array}$ \\
\hline & $\begin{array}{l}\text { By } 2030 \text { in Western Europe, UK, } \\
\text { USA, Canada, Australia and New } \\
\text { Zealand, Japan, Mexico } \\
\text { By } 2045 \text { in China, India, South } \\
\text { Korea, Other Developing Asia, } \\
\text { Eastern Europe } \\
\text { Late phase-out in Central and } \\
\text { South America, Former Soviet } \\
\text { union, Middle East, Africa }\end{array}$ & Endogenous & Endogenous & Endogenous \\
\hline & & & & $\begin{array}{l}\text { Achieving global change in diet, based } \\
\text { on the Eat Lancet_Commission (Willett } \\
\text { et al., 2019) }\end{array}$ \\
\hline & & & & $\begin{array}{l}\text { Limit to } 2 \text { trillion veh-km/a for road and } \\
2 \text { trillion t-km/a for rail till } 2030 \text { (based } \\
\text { on IEA ETP 2012) }\end{array}$ \\
\hline \multirow[t]{2}{*}{$\begin{array}{l}\text { Renewable en- } \\
\text { ergy generation }\end{array}$} & $\begin{array}{l}\text { Capacity growth limited to } 30 \% \\
\text { p.a. }\end{array}$ & $\begin{array}{l}\text { Capacity growth limited to } \\
30 \% \text { p.a. }\end{array}$ & $\begin{array}{l}\text { Regional constraints on capac- } \\
\text { ity addition, total limit, and ca- } \\
\text { pacity growth }\end{array}$ & $\begin{array}{l}\text { - Capacity growth limited to around } 10 \% \\
\text { p.a. }\end{array}$ \\
\hline & $\begin{array}{l}\text { Combined on- and off-shore winc } \\
\text { capacity growth limited to } 20 \% \\
\text { p.a. }\end{array}$ & $\begin{array}{l}\text { dOn shore wind capacity } \\
\text { growth limited } \\
\text { to } 10 \% \text { p.a. upto } 2040 \text { and } \\
3.5 \% \text { p.a after } 2040 \text { and off- }\end{array}$ & $\begin{array}{l}\text { Regional constraints on capac- } \\
\text { ity addition, total limit, and ca- } \\
\text { pacity growth }\end{array}$ & $\begin{array}{l}\text { Combined on- and off-shore wind ca- } \\
\text { pacity growth limited, to } 10 \% \text { p.a. }\end{array}$ \\
\hline
\end{tabular}


shore wind capacity growth

limited to $20 \%$ p.a

CCS

Electricity and heat, hydro-

Electricity and heat, hydrogen,

industry

Electricity and heat; hydrogen, Electricity

and biofuel production;

industry

$2-5 \%$ per year

$2-5 \%$ per year

Regional constraints on capac- Max activity constrained to $10 \mathrm{EJ}$ p.a. ity addition, total limit, and ca-

Limited to 115 GtCO2 cumulative Limited to $9392 \mathrm{GtCO} 2 \mathrm{cu}-$

over 2030-2060 mulative over 2025-2100

$\mathrm{CO}_{2}$ remova

BECCS, DACS

BECCS, DACS

BECCS

BECCS, Forest land acting as carbon sink 


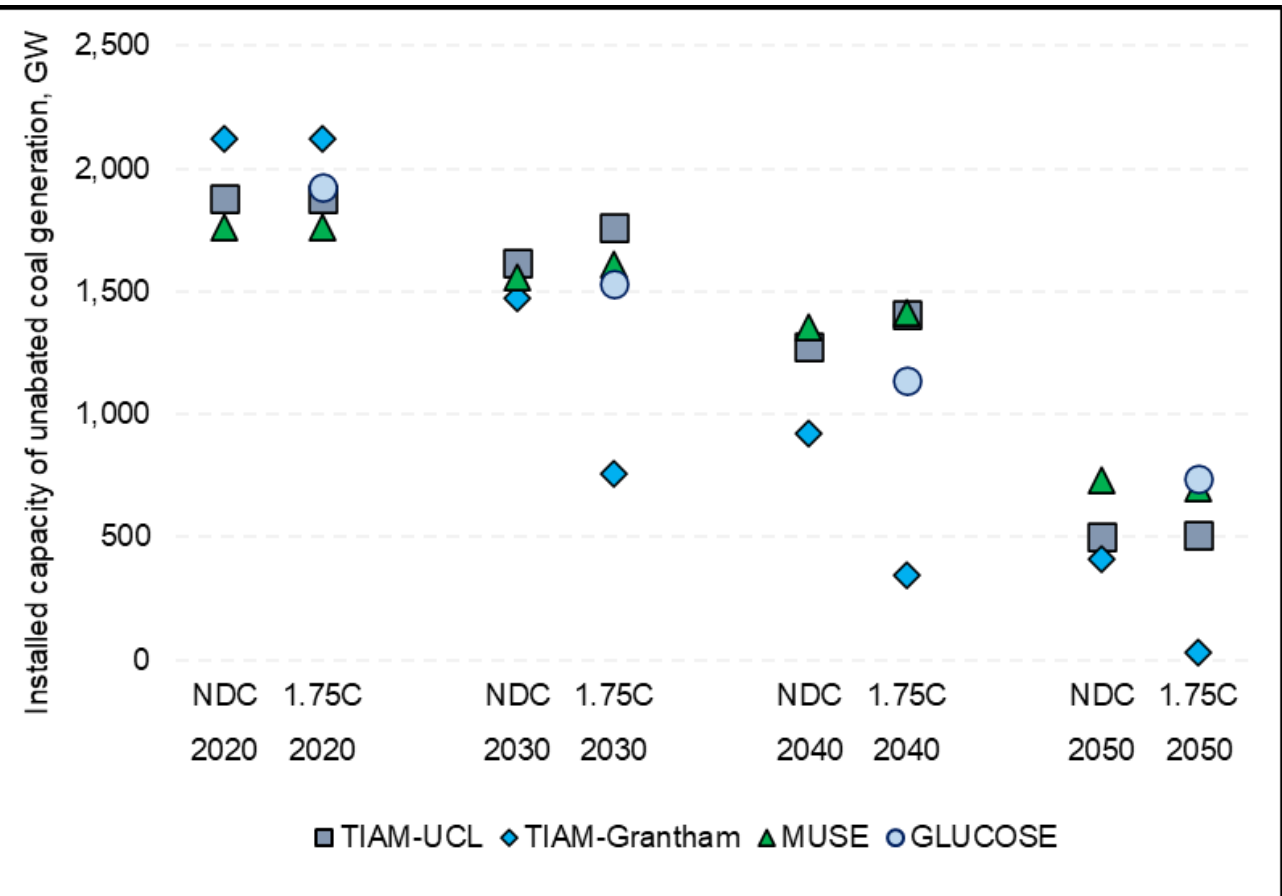

Figure C1. Installed capacity of global unabated coal generation, 2020-50. There is variation in 2020 levels between models as this a projected year, with capacity data only available for 2019.

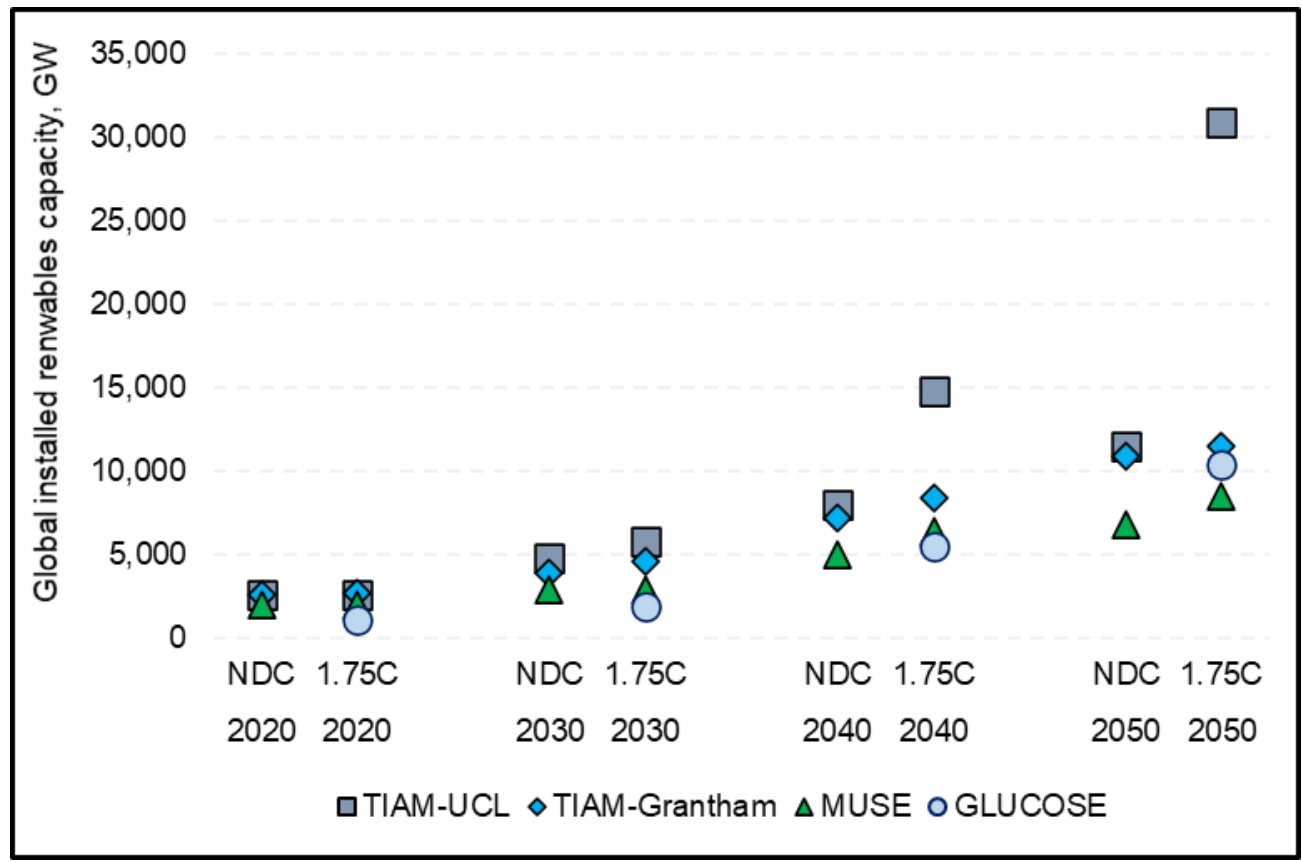

Figure C2. Global renewable generation capacity (excluding bioenergy), 2020-50. There is variation in 2020 levels between models as this a projected year, with capacity data only available for 2019. 
a)

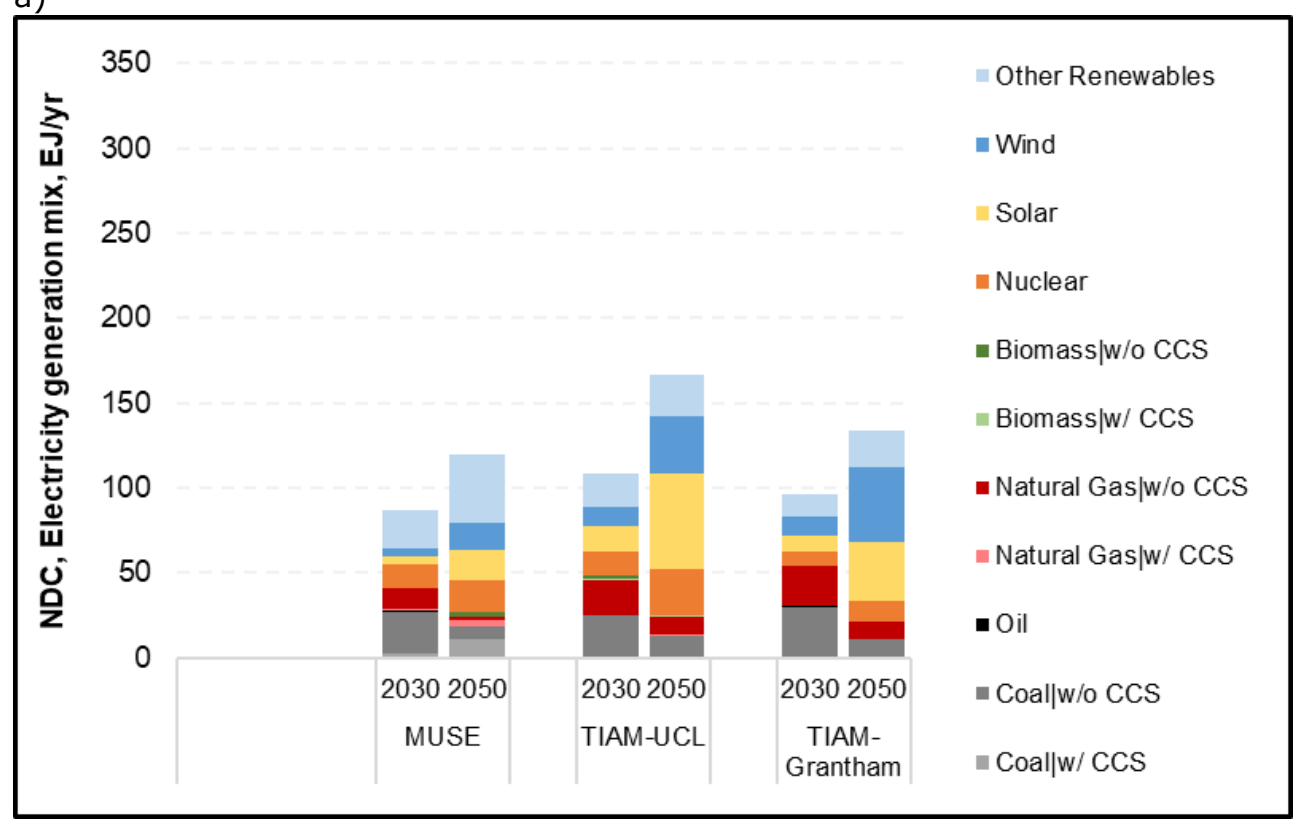

b)

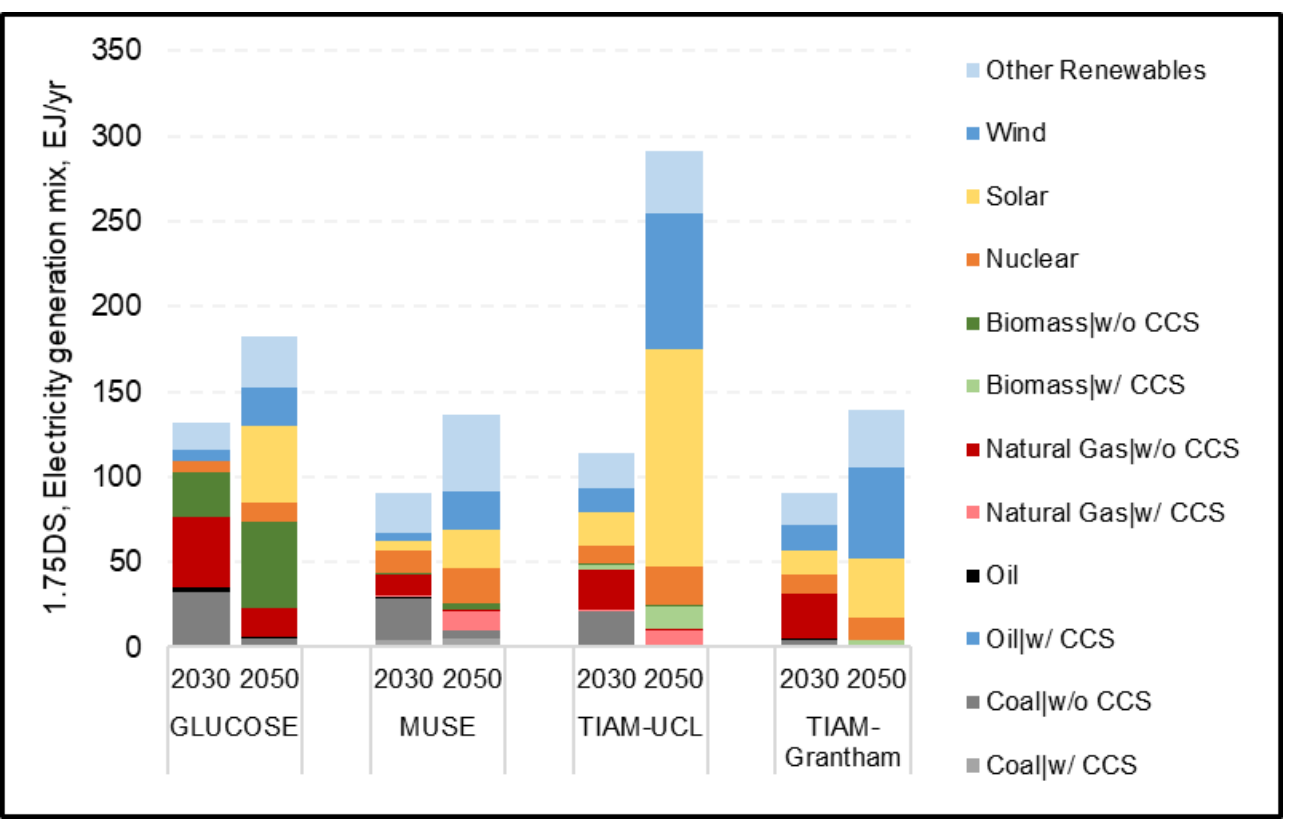




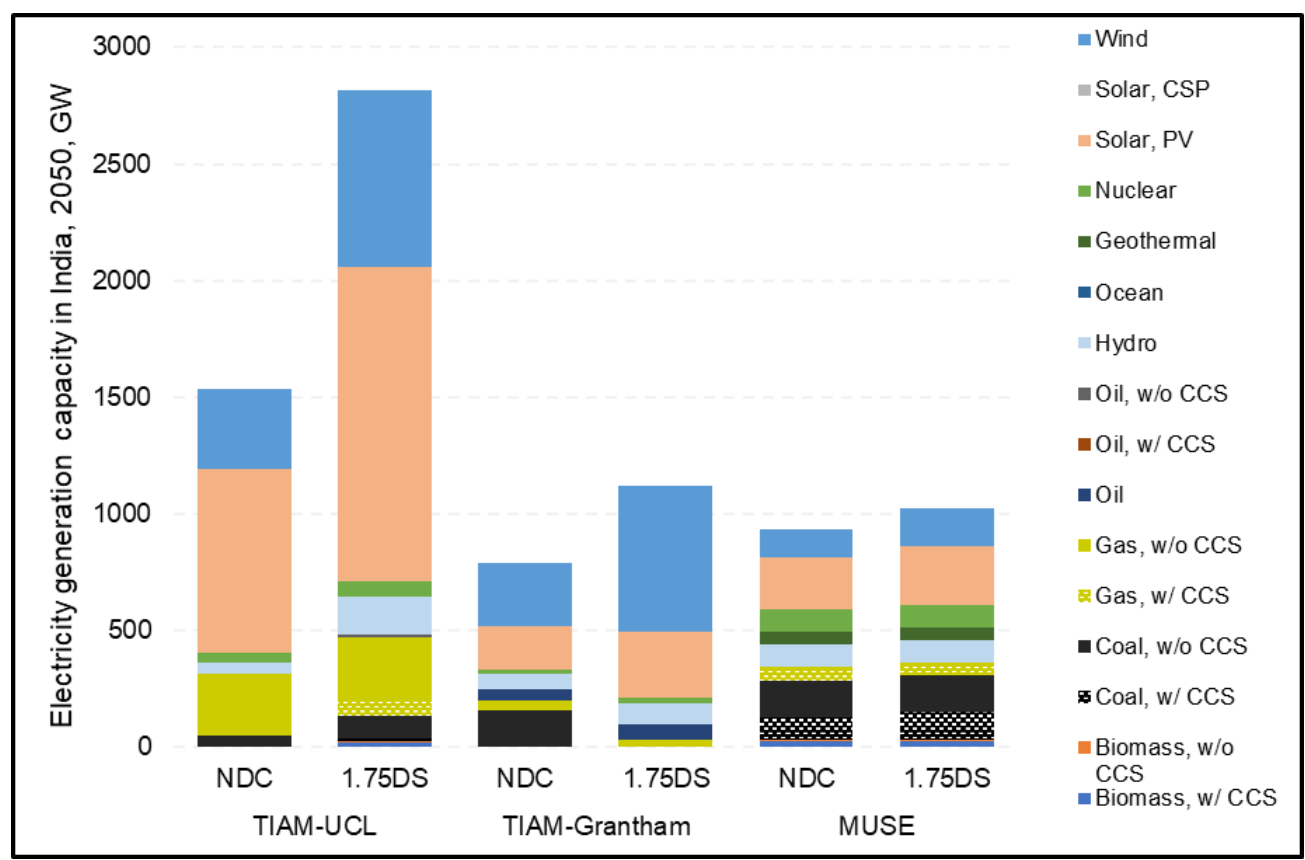

Figure C4. Installed capacity of the electricity generation sector in India, 2050, in selected IAMs, under NDC and $1.75^{\circ} \mathrm{C}$ scenarios 
Figures

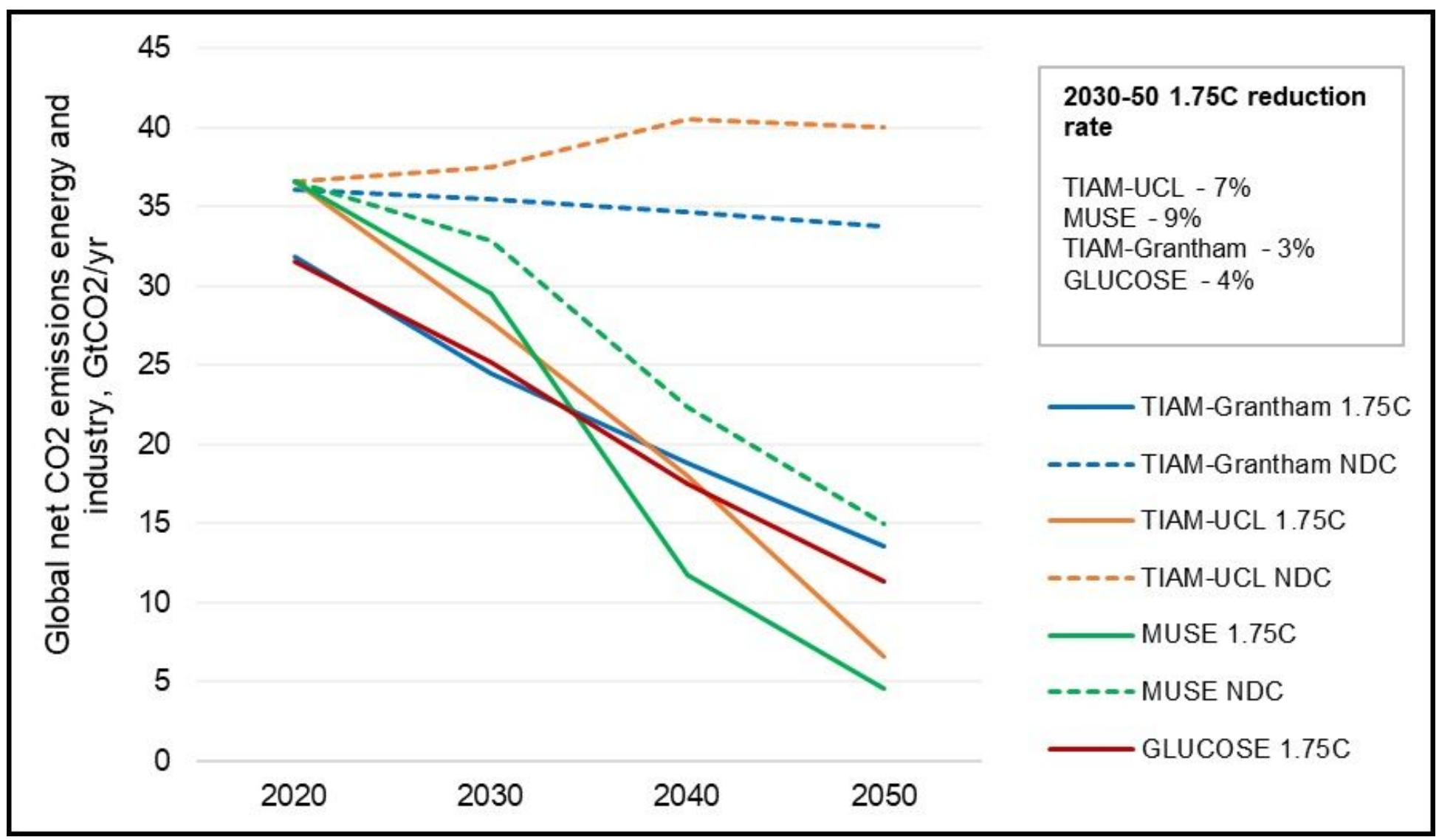

Figure 1

Global net $\mathrm{CO} 2$ emissions from energy use and industrial processes for NDC and $1.75^{\circ} \mathrm{C}$ scenarios, 202050. This graph only includes $\mathrm{CO} 2$ emissions from energy use and indus-trial processes, net of engineered removals (CCS / DAC).2 AFOLU emissions are not presented, but are included in the analysis for TIAMUCL and GLUCOSE. Some differences in 2020, showing lower emissions, reflect 2020 being a modelled rather than a calibrated period. 


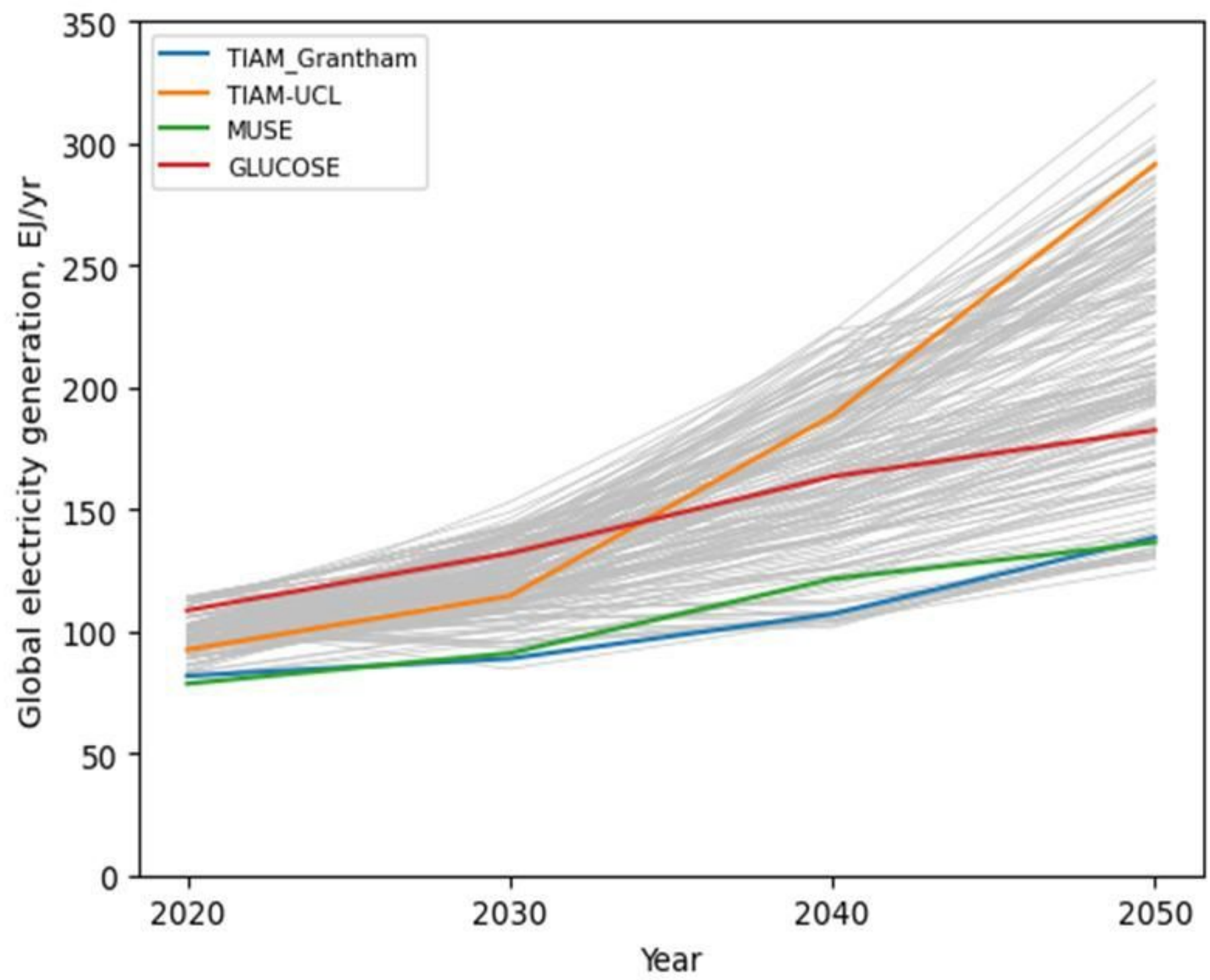

Figure 2

Global electricity generation for selected models for a $1.75^{\circ} \mathrm{C}$ target compared to SR 1.5 scenario ensemble, 2020-50. Differences around the 2020 level reflect that this is a modelled period. IEA (IEA, 2020) reports the generation level at 97 EJ in 2019. 


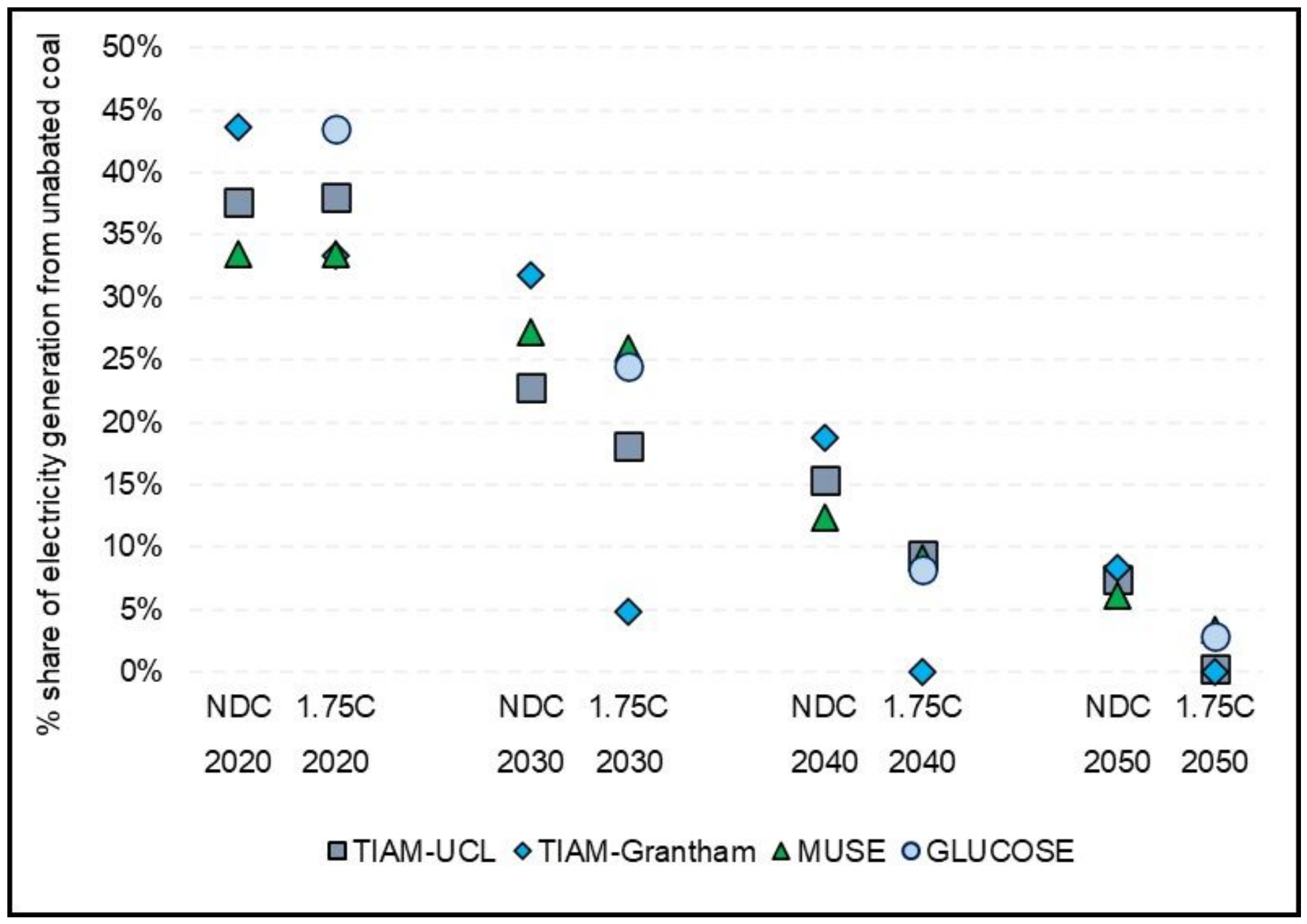

Figure 3

Global unabated coal generation as share of total generation for NDC and $1.75^{\circ} \mathrm{C}$ scenarios, $2020-50$. Differences around the 2020 level reflect that this is a modelled period; hence the variation between models. Another reason is the inclusion or not of own producers of electricity, particularly in the industrial sector. IEA (IEA, 2020) reports the coal share at 37\% in 2019. 

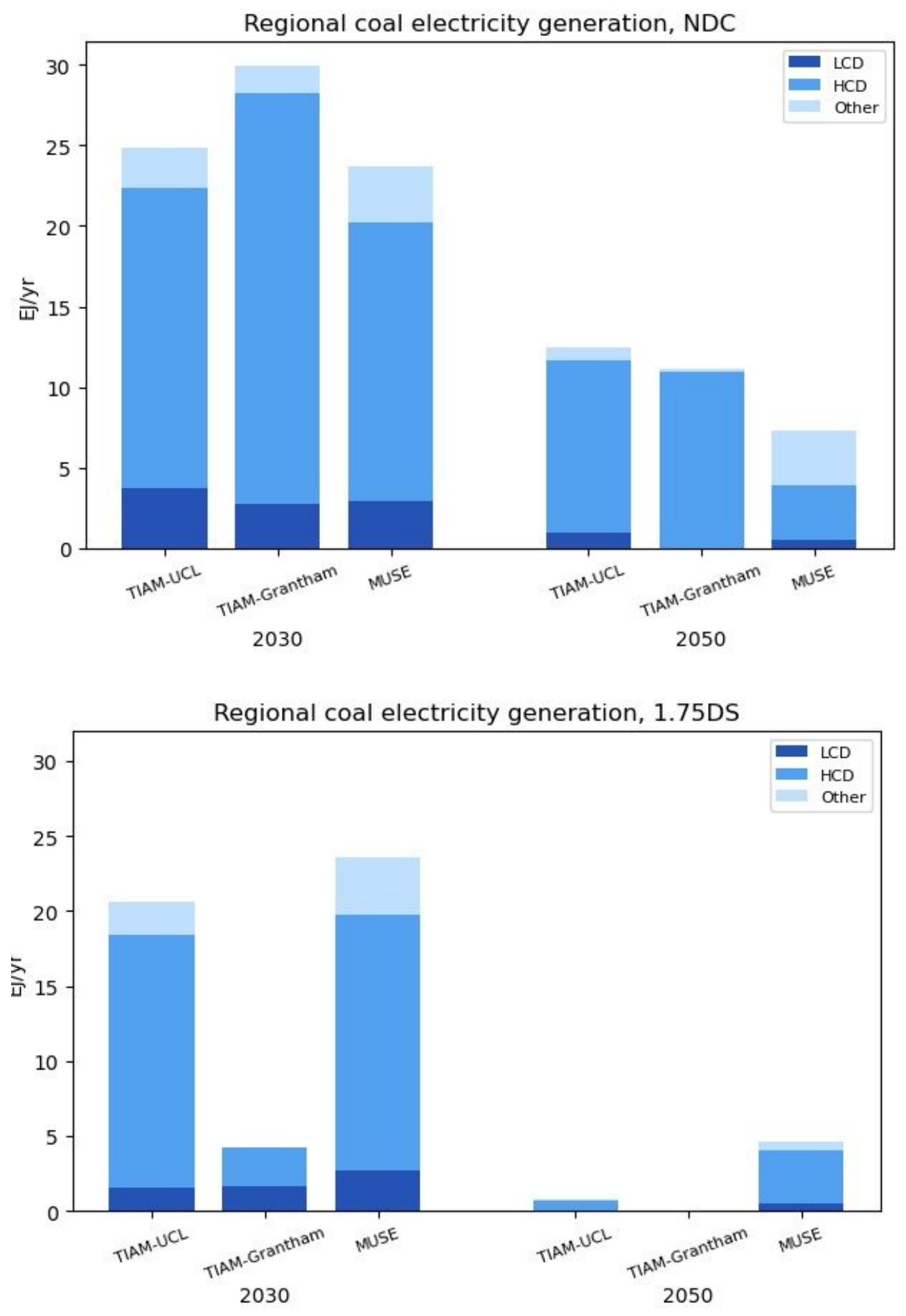

Figure 4

Regional generation from unabated coal under NDC (upper panel) and $1.75^{\circ} \mathrm{C}$ (lower panel) scenarios, 2020-50. Global generation in 2019 was in the region of 35 EJ. LCD = Lower Coal Dependent; HCD = Higher Coal Dependent. 


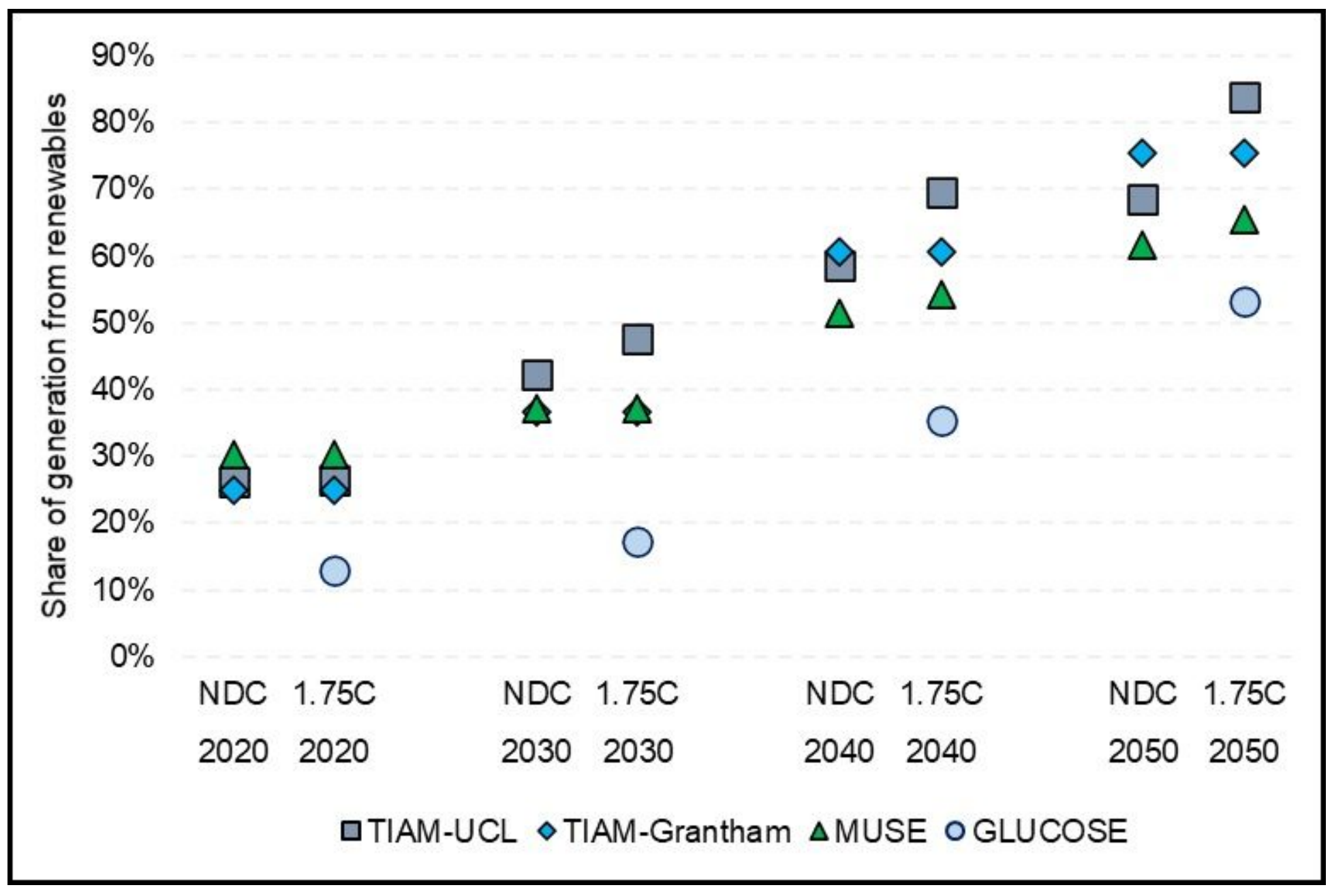

Figure 5

Shares of renewables (excluding bioenergy) as a percentage of total global generation, 2020-50. Differences around the 2020 level reflect that this is a modelled period. IEA (2020) reports the share of renewables (excluding bioenergy) to be $27 \%$ in 2019. 

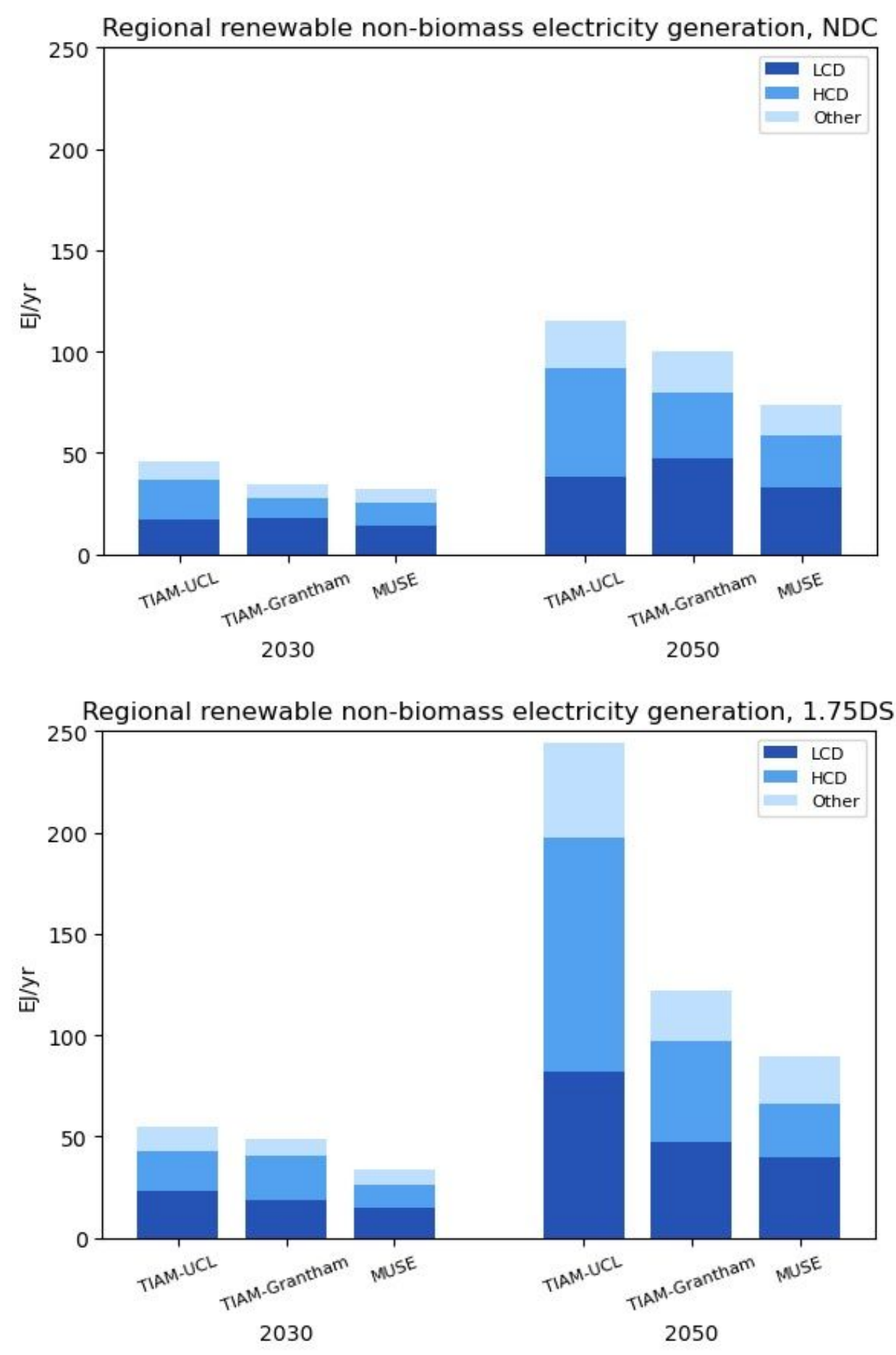

\section{Figure 6}

Regional generation from non-bioenergy renewables under NDC (upper panel) and $1.75^{\circ} \mathrm{C}$ (lower panel) scenarios, 2020-50. Global non-bioenergy renewable generation in 2019 was in the region of $23 \mathrm{EJ}$. LCD = Lower Coal Dependent; HCD = Higher Coal Dependent. 


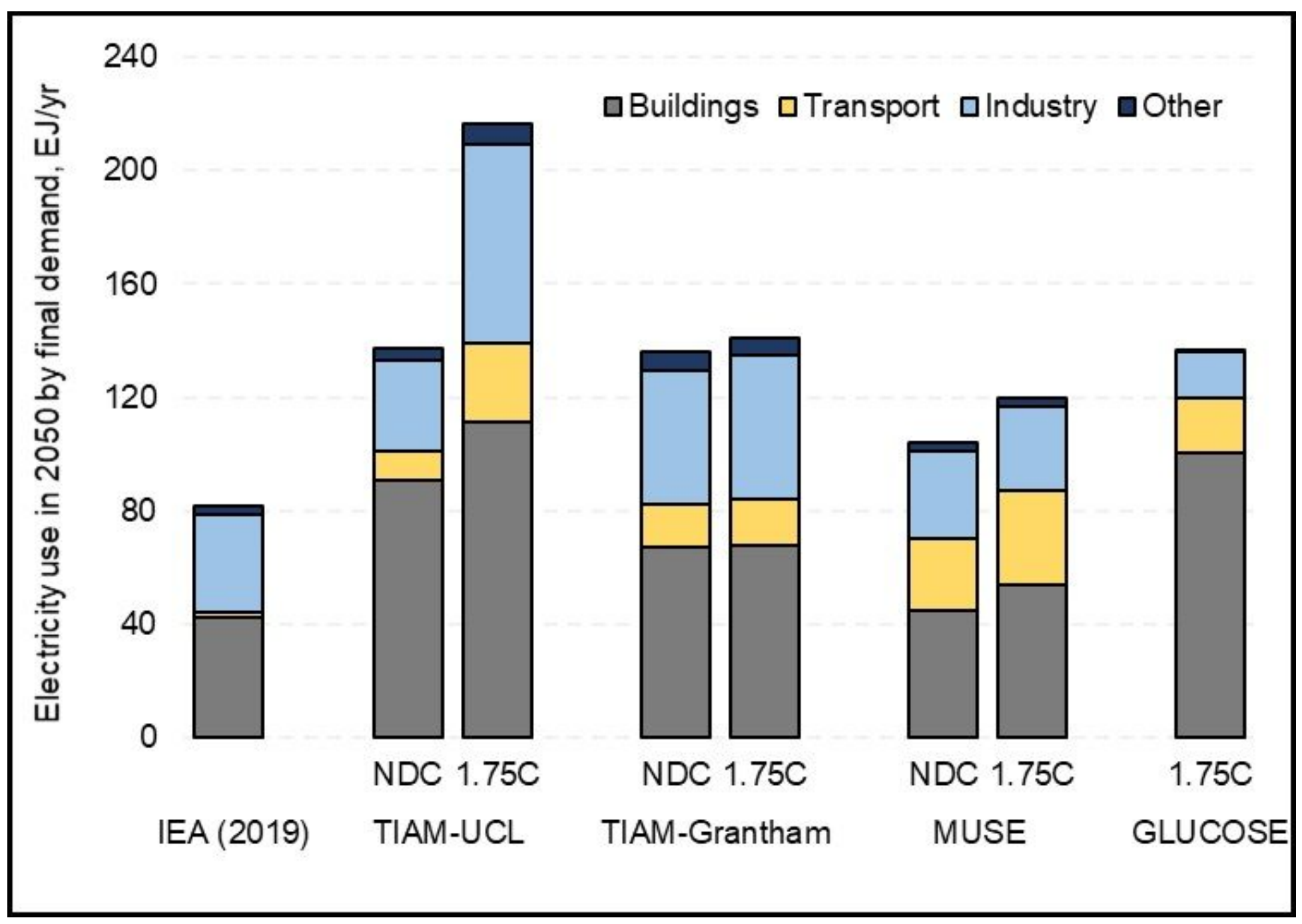

Figure 7

Electricity consumption by end use sector in 2050 , under NDC and $1.75^{\circ} \mathrm{C}$ cases 


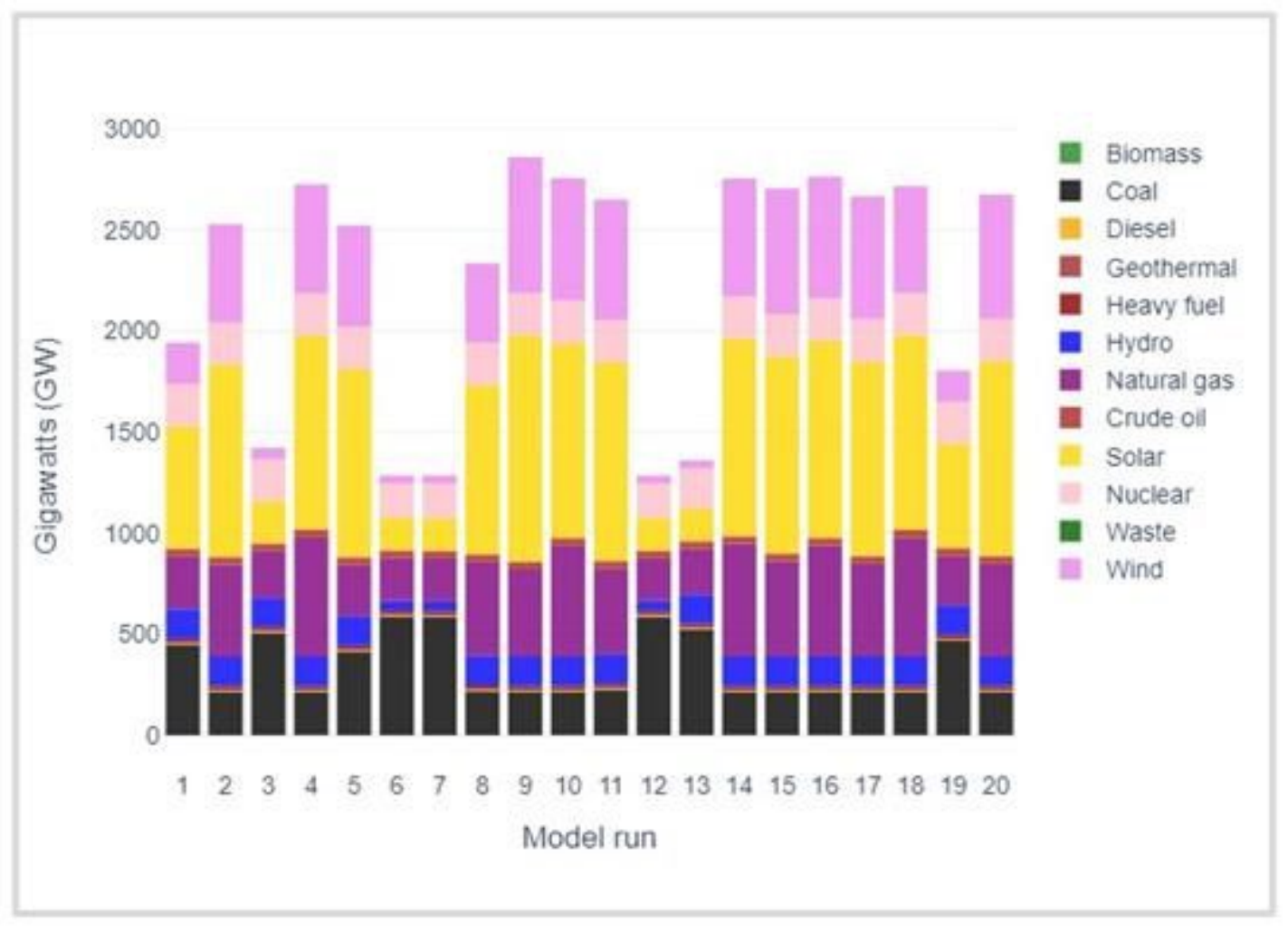

\section{Figure 8}

Power generation capacity mix across 20 scenarios run in the OSeMOSYS Global model for the GCC-India region, 2050. The capacity mix from the global IAMs for India in 2050 can be found in Appendix C.

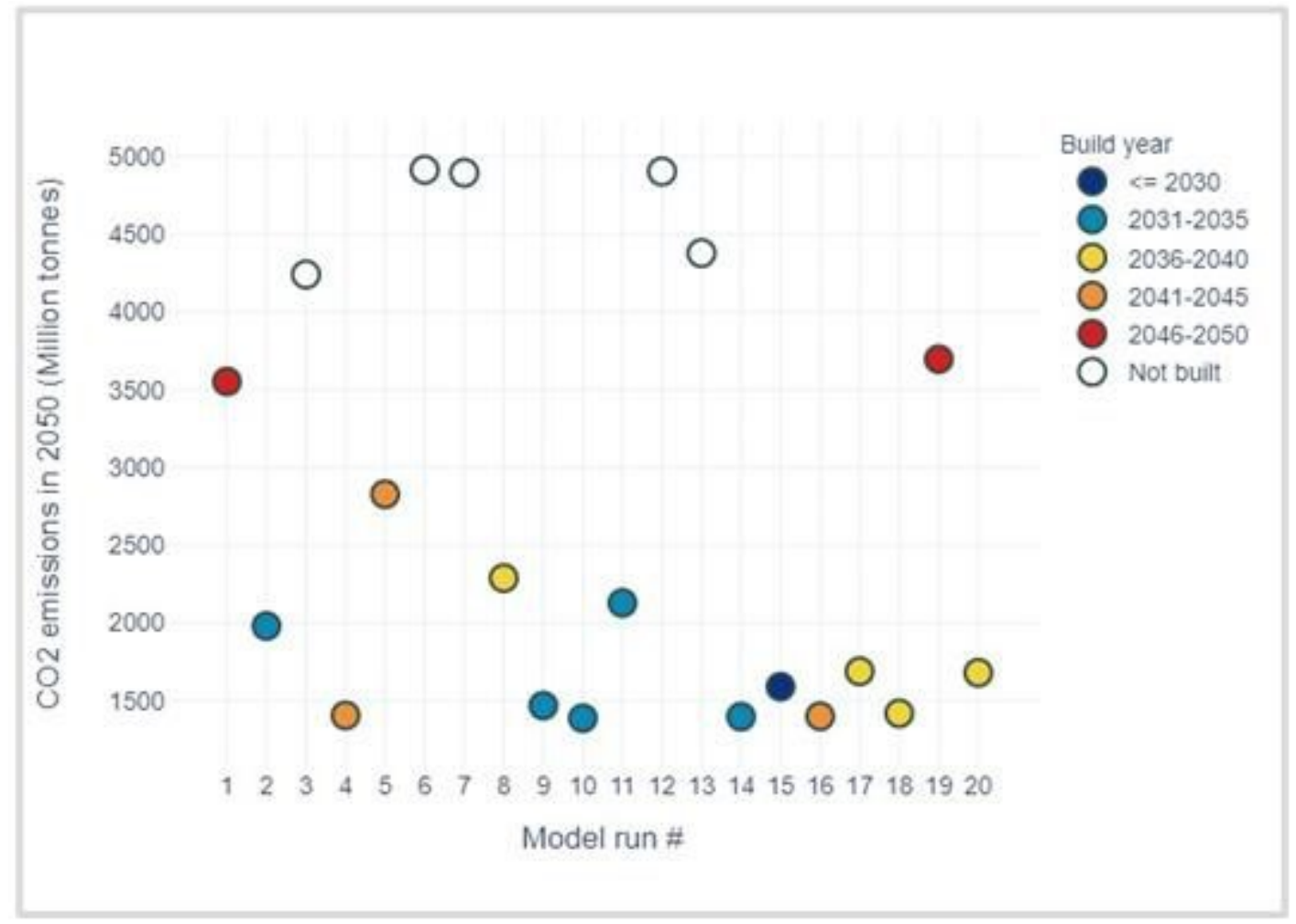

Figure 9 


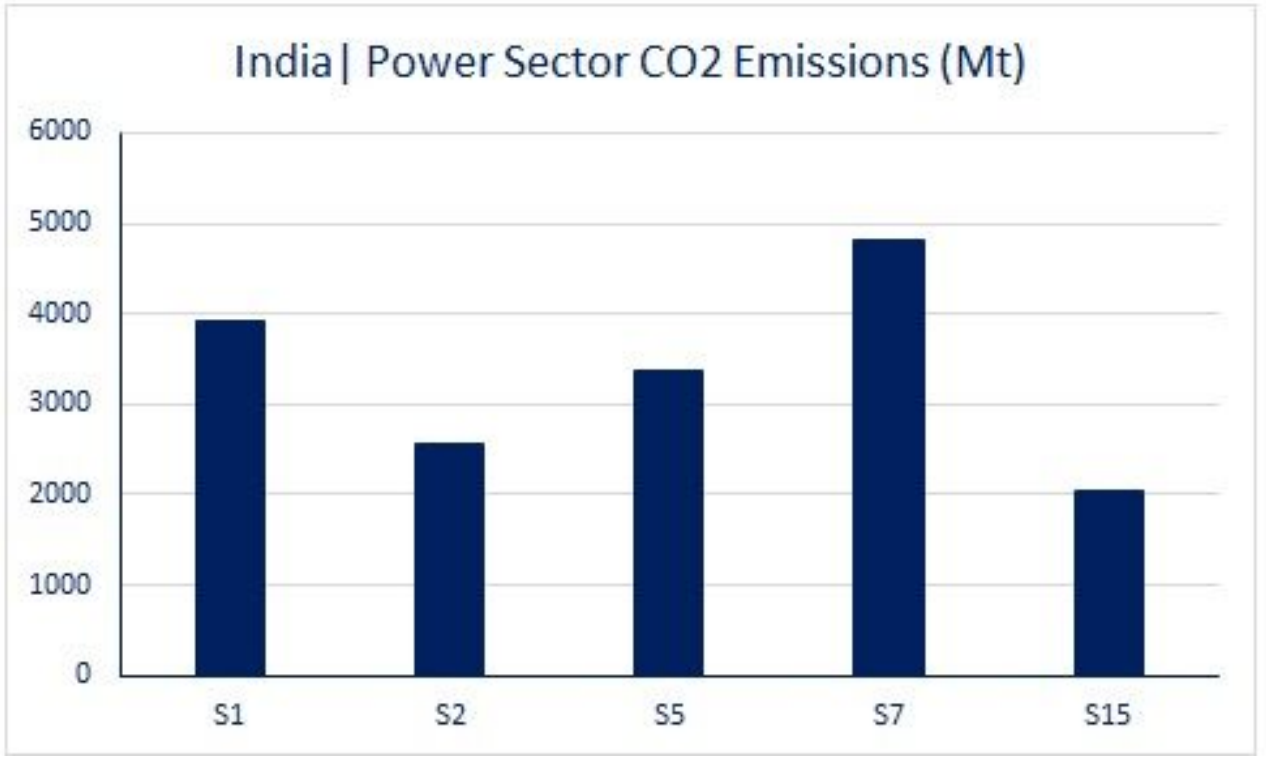

Figure 10

Power sector CO2 emissions in India for five selected scenarios, 2050

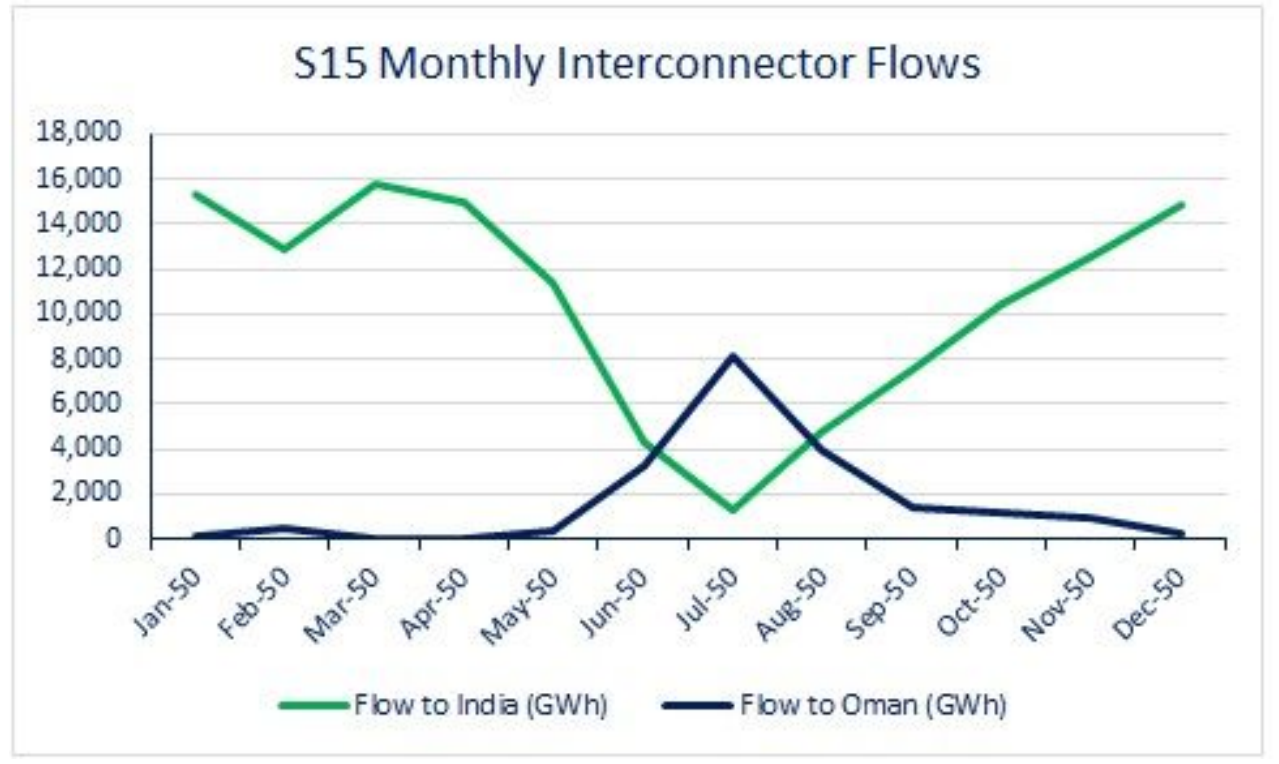

Figure 11

Monthly interconnector flow for the GCC-India scenario 15, 2050 


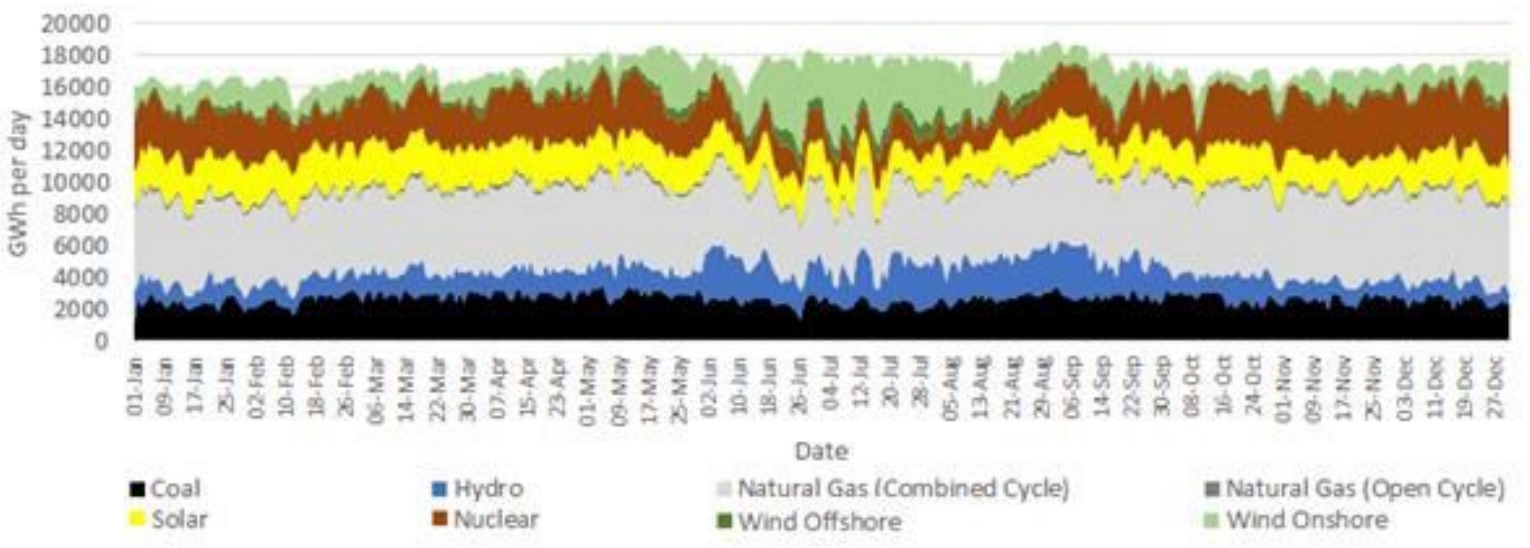

Figure 12

Daily generation by fuel in India for scenario 15, 2050
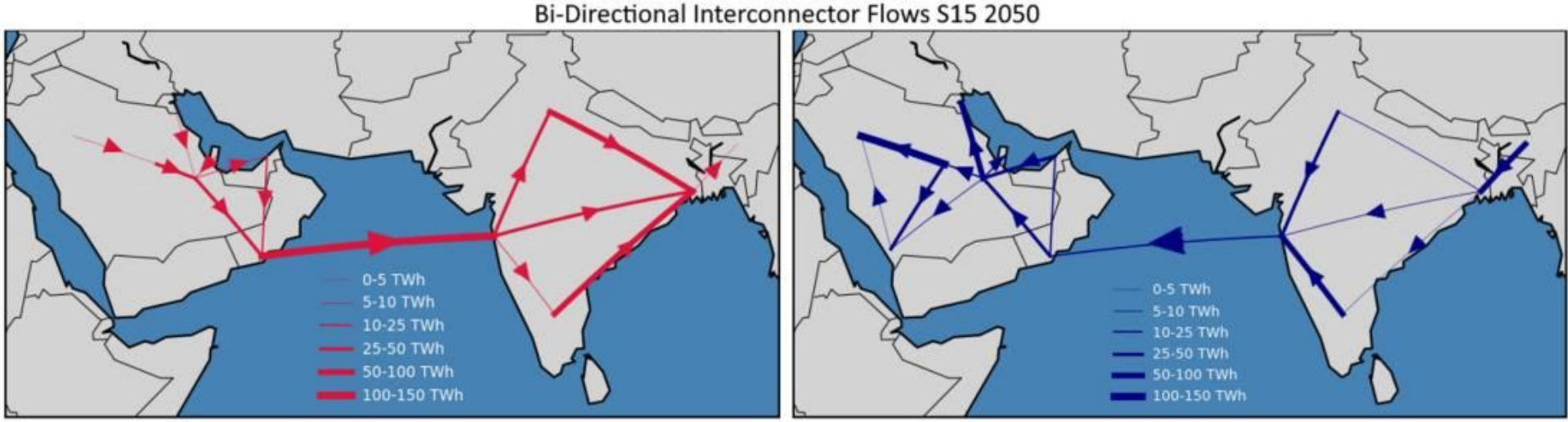

Figure 13

Bi-directional interconnector flows for scenario 15, 2050 